r

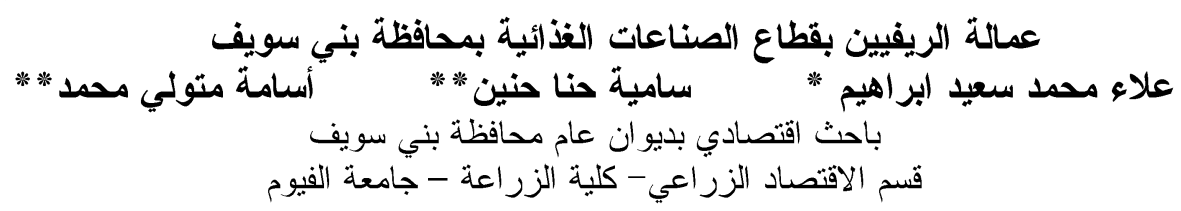

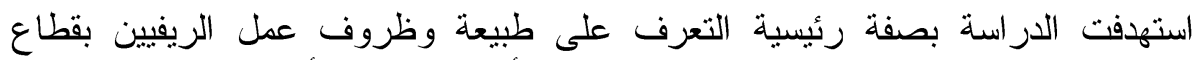

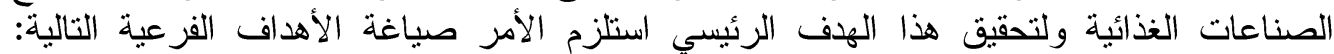

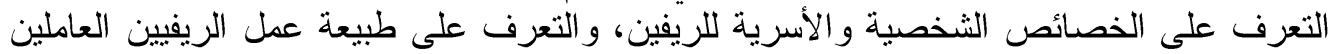

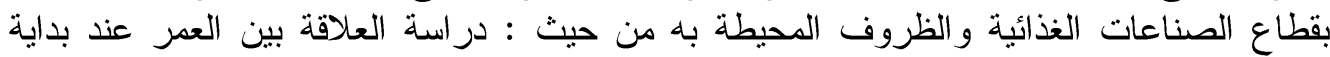

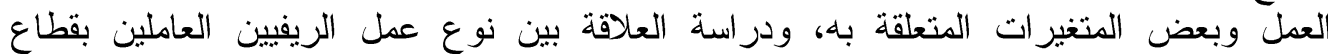

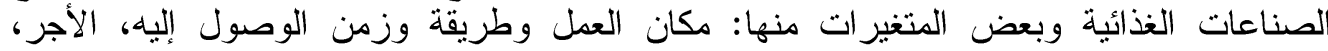

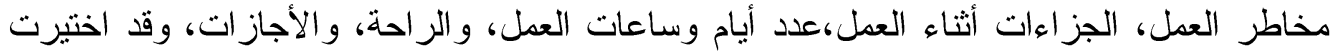

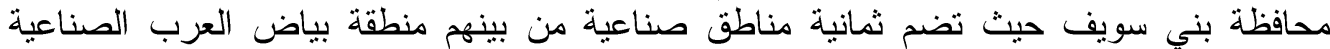

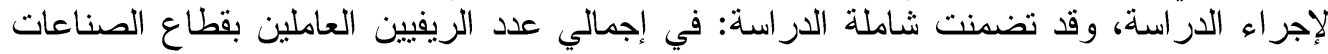

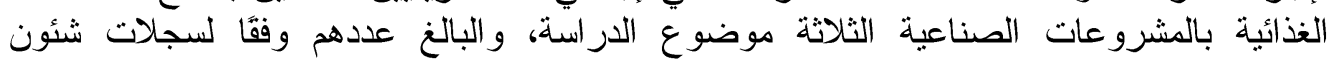

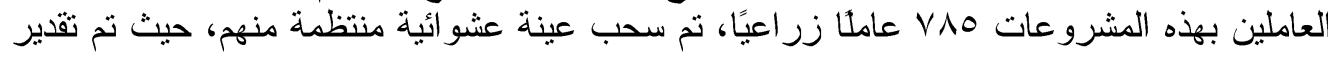

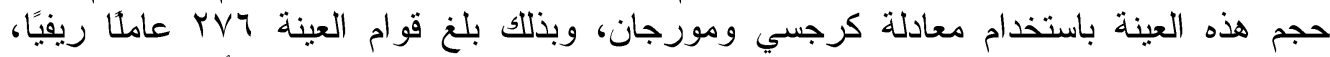

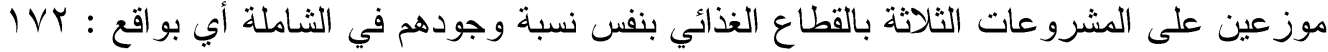

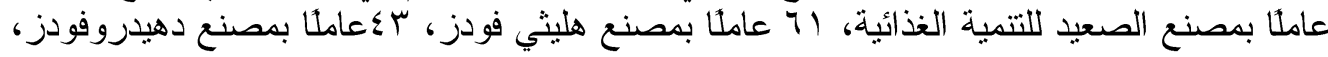
وللحصول على البيانات الميدانية اللازمة للار اسة حيث تم تصميم صحيفة استبيان: خاصة بالريفين دهاني

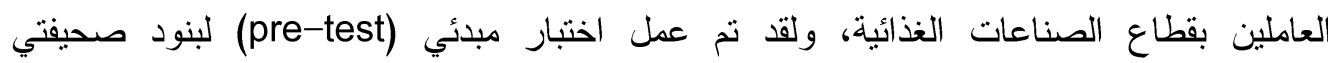

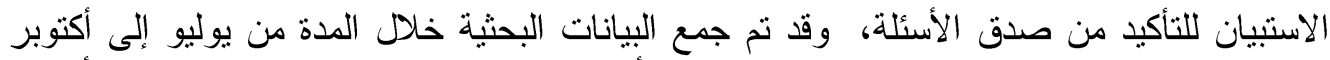

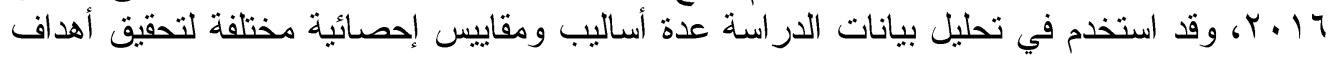

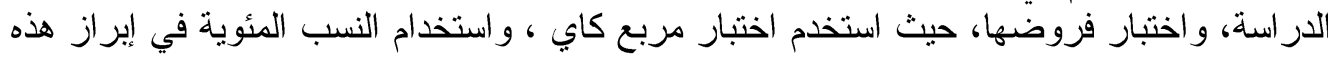

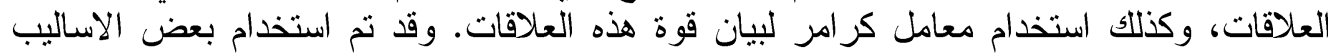

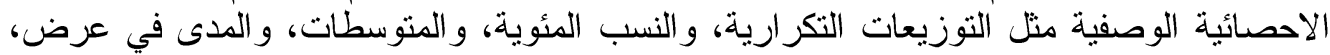
ووصف متغير ات الدر اسة.

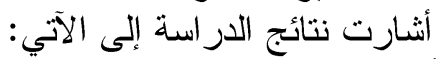

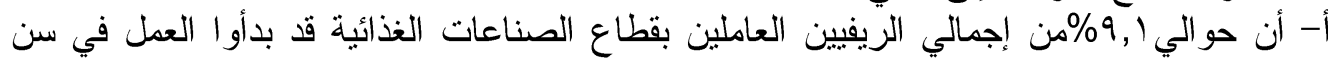

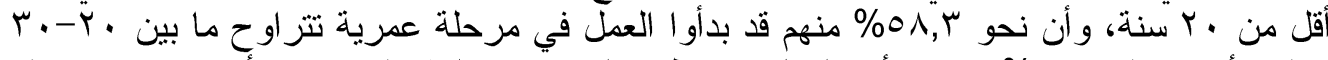

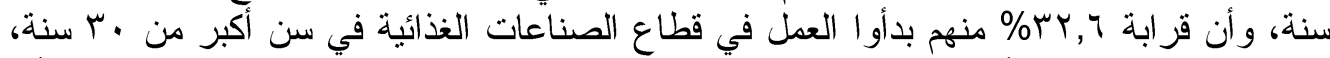

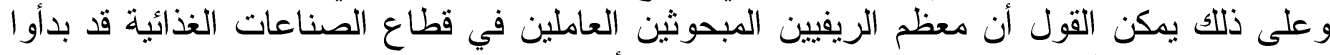

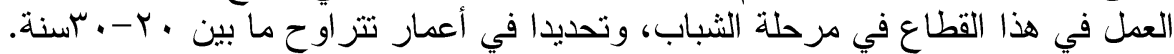

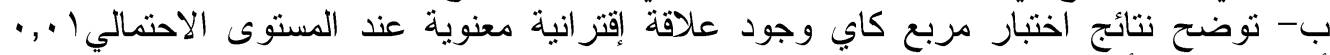

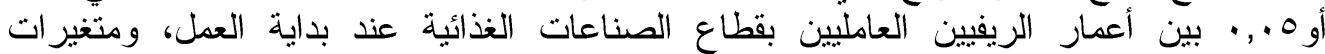

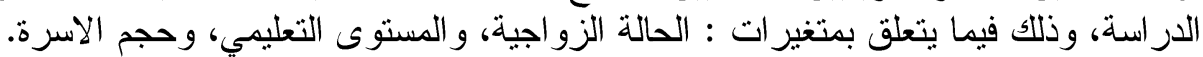

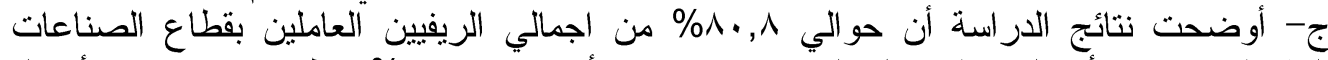

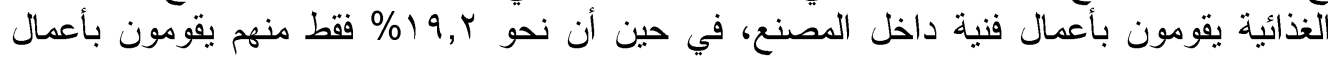

Fayoum J. Agric. Res. \& Dev., Vol. rr, No. ', July, r. IA 
rv

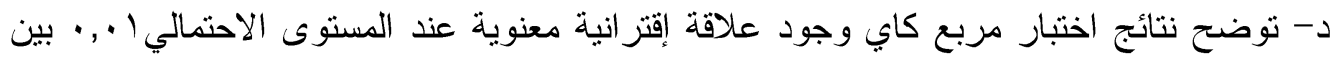

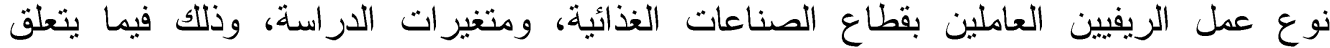
بمتغيرات : النوع، والمستوى التعليمي، ووجود مهنة اضافية، وحجم الأسرة، ونوع الأنيزة الاسرة،

ومستوى المعيشة.

وقد انتهت الدراسة الى مناقثة لأهم نتائجها وتقديم مجموعة من التوصيات قد تقبد في زيادة اتجاهات الريفيين للعمل بالمناطق الصنات الصناعية.

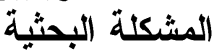

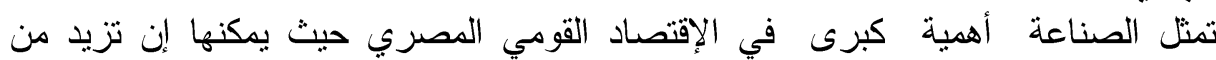

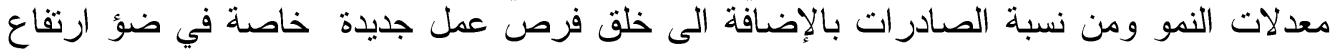

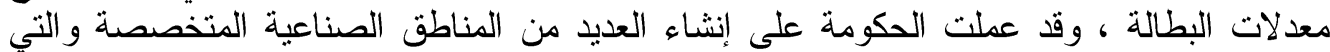

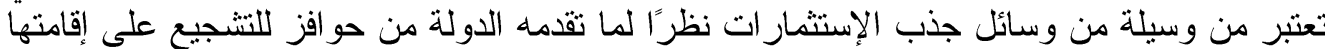

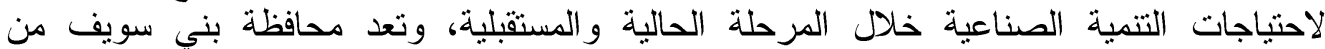

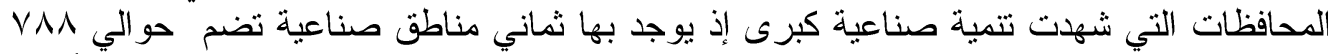

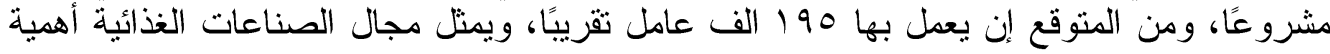

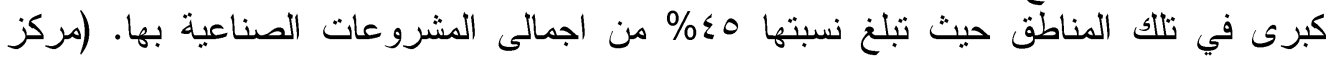

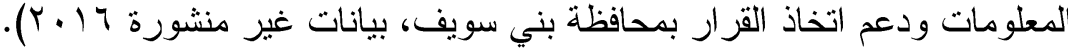

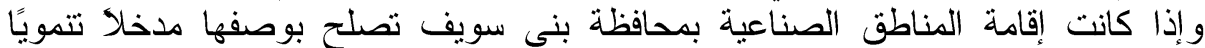

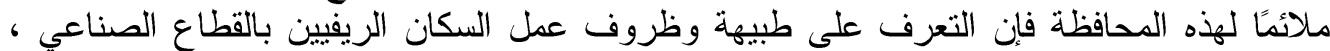

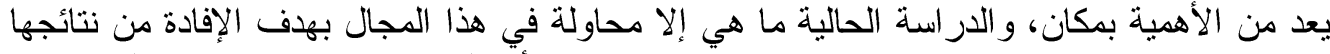

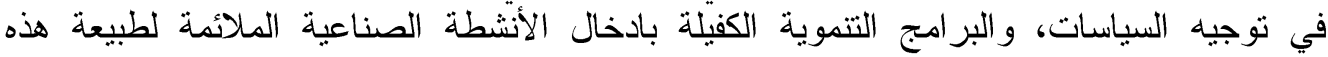

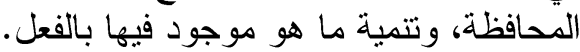

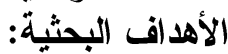

استهدفت الدراسة بصفة رئيسية التعرف على طبيعة وظروف عمل الرئية الريفين بقطاع الصناعات

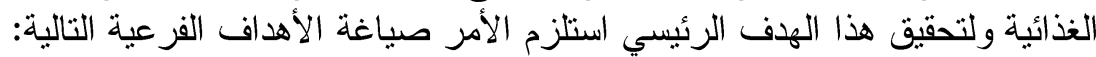

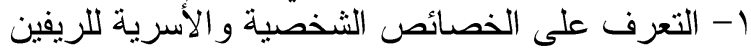

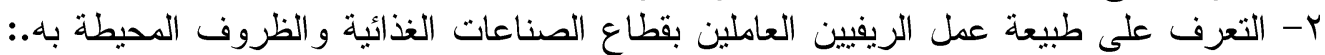

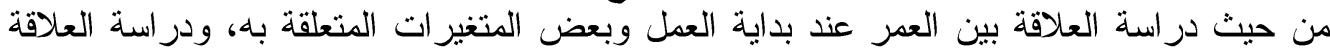

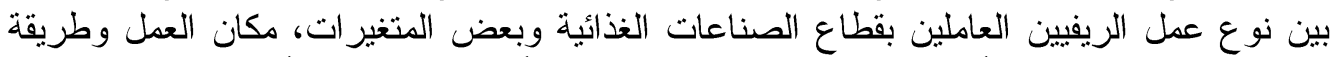

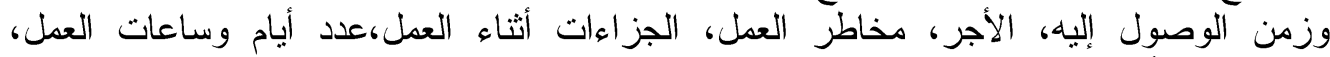

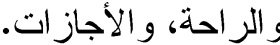

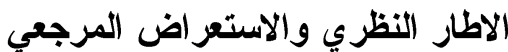
أولا: مفهوم التصنيع والإن المفاهيم ذات التعلاقة

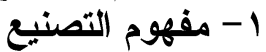

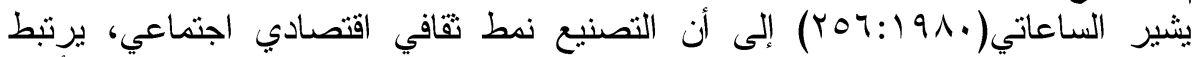

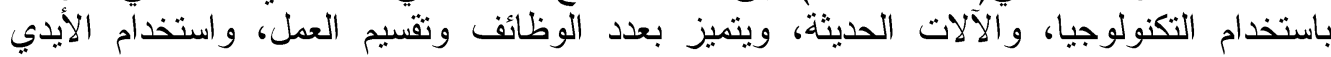

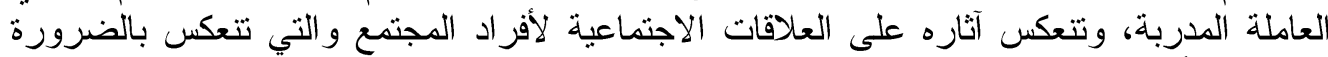
على قيم الأفر اد وسلوكهم الاجتماعي في المجتمع الصناعي.

Fayoum J. Agric. Res. \& Dev., Vol. rr, No. ', July, r. IA 
$\mu \wedge$

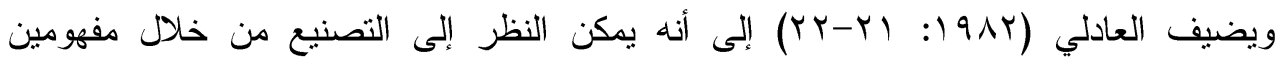
: أساسبين

ا-1المفهوم الاقتصادي للتصنيع: و الذي يعتبر التصنيع نشاطا هادفا لقطاع من الاقتصاد العام

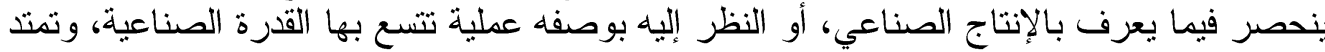

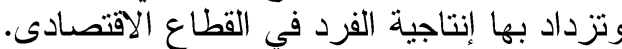

r- المفهوم الاجتماعي للتصنيع: حيث يرى أن أن التصنيع عملية اجتماعية شاملة ذات بلتية بداية وتسير في حلقات كبرى مرتبطة بعضها ببعض، وتكون كل حلقة منها بدور ها عملية فرعية بذاتها،

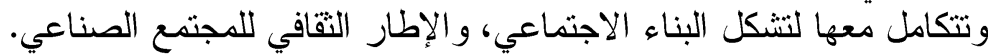

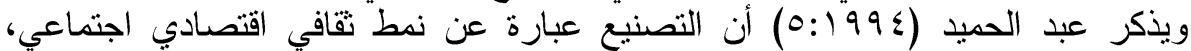
يرتبط باستخدام التكنولوجيا والآلات الحديثة، ويتمبز بعدد الوظائف، وتقسيم العمل، و استخدام الأيدي

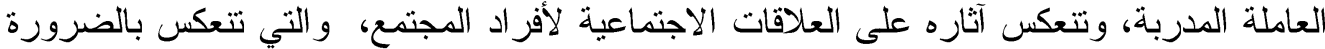
على قيم الأفر اد، وسلوكهم الاجتماعي في في المجتمع الصناعي.

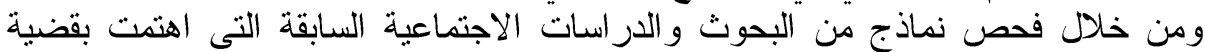

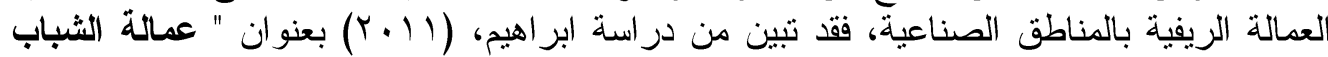

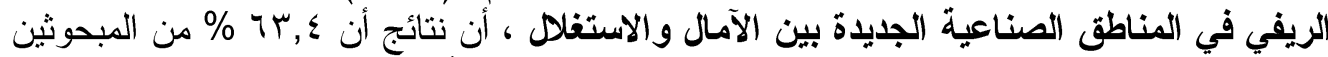

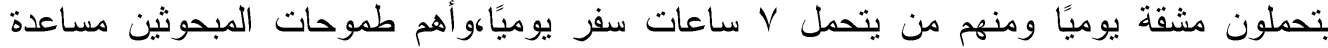

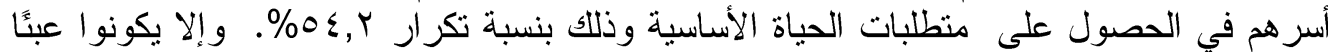

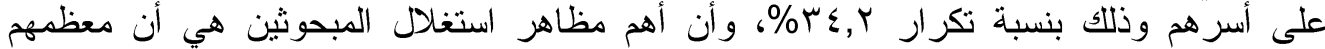

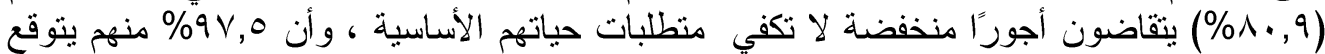

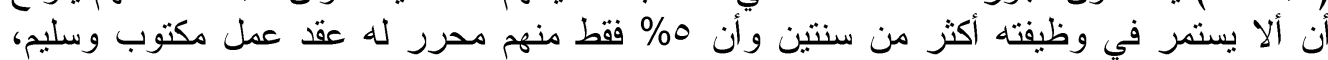

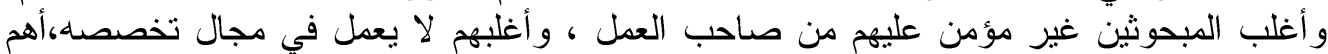

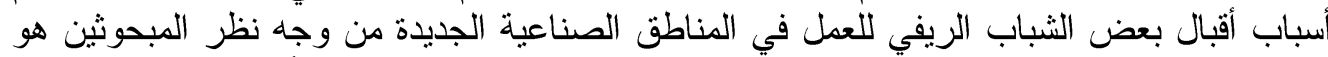

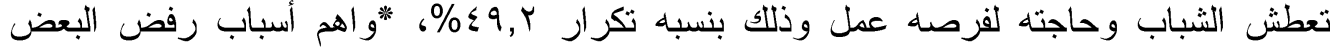

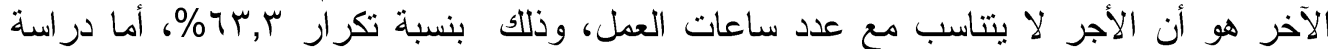
السيد بعنوان" اغثراب الشباب في التنظيمات الاجتماعية الصناعية- در استة ميدانية في احدى القية القرى

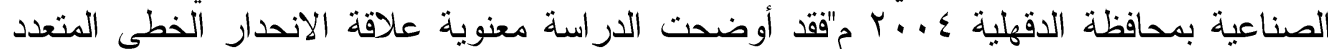

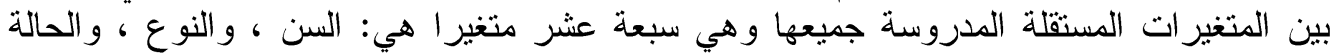

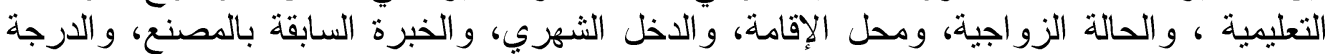

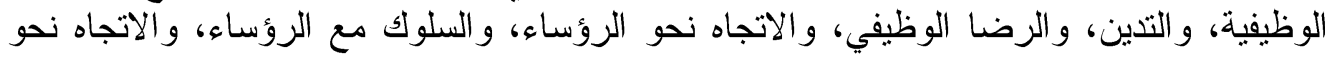

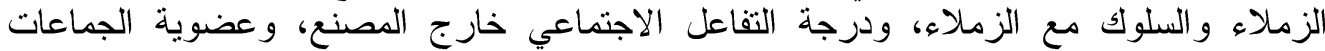

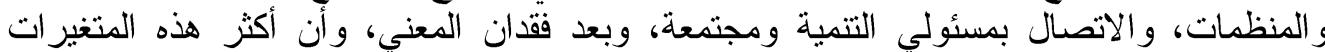

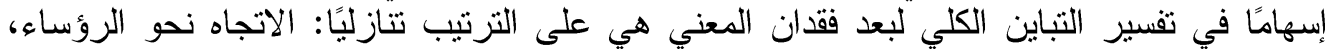

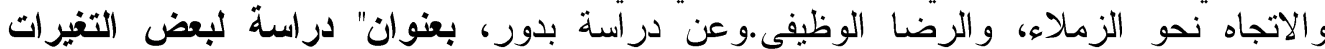

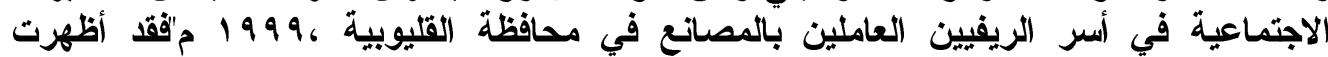

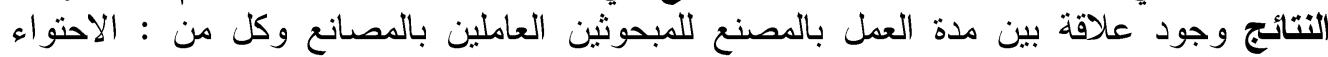

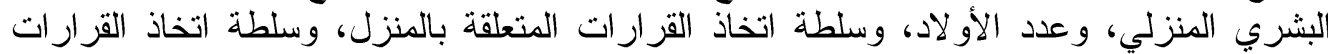
المتعلقة بالعمل الزراعي، وشدة العلاقة مع الجيران، و الاعتماد على السوق لتحقيق متطلبات الحياة

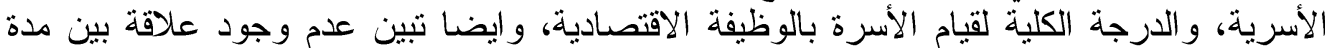

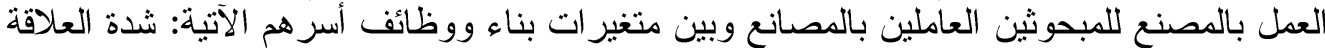

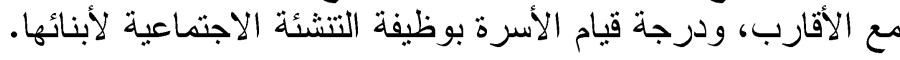

Fayoum J. Agric. Res. \& Dev., Vol. 'r,, No. ', July, ґ. I^ 
تحقيقا لأهداف الدرة اسة وبناءً على الإطار النظرى، ونتائج البحوث، و الدراسات السابقة

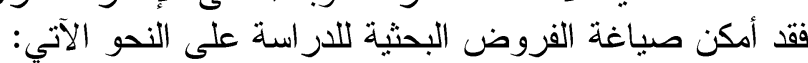

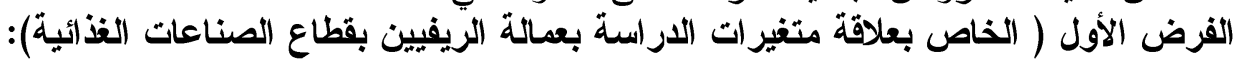

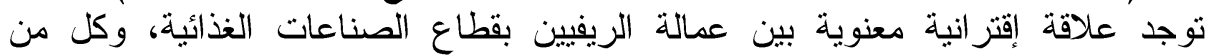

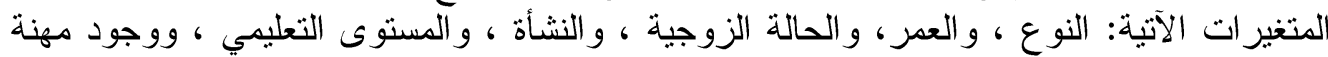

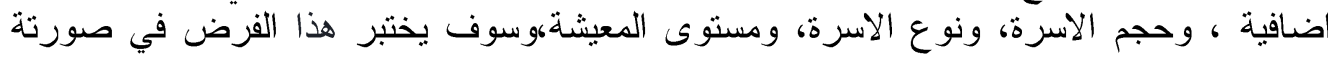

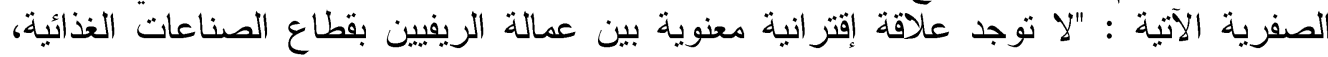

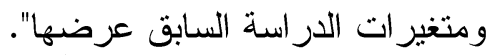

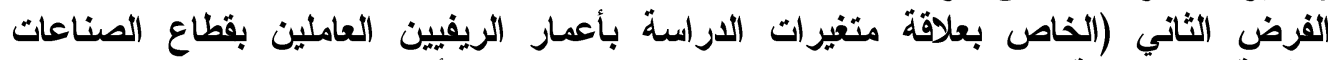

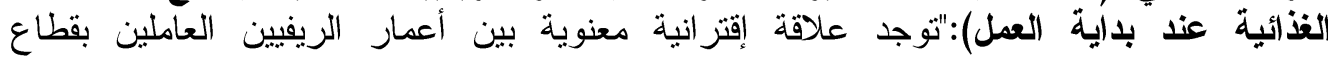

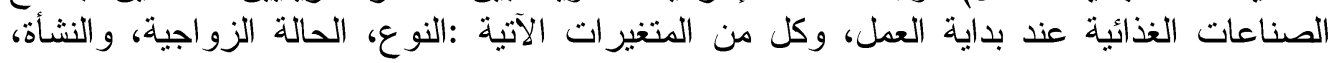

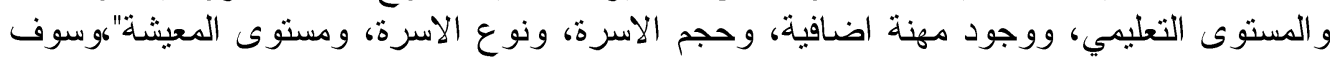

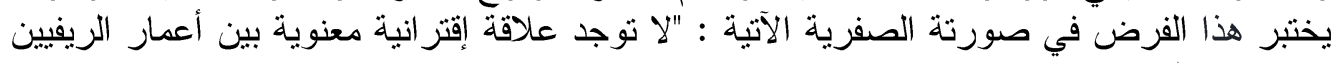

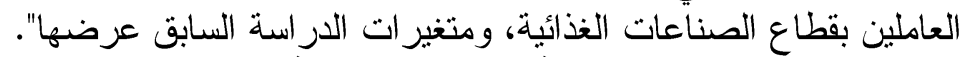

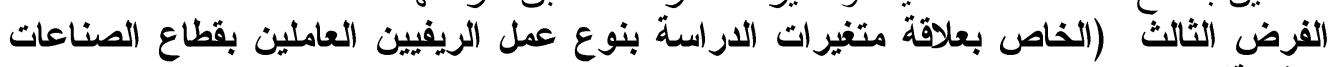

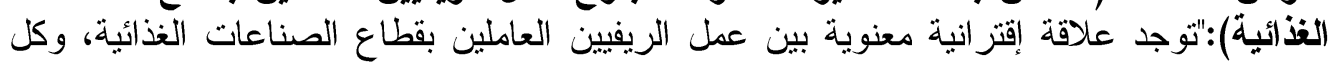

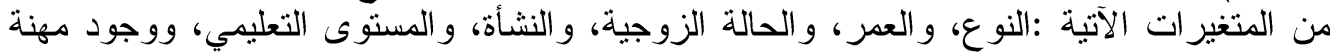

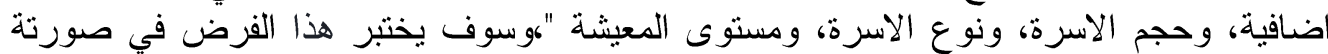

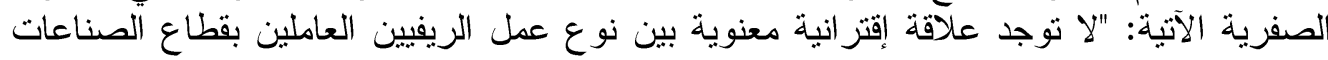

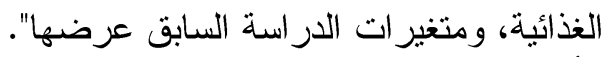

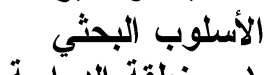

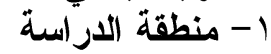

تم اختيار محافظة بني سويف لإجراء الدراسة عليها فهي تعد إحدى محافظات إقليم

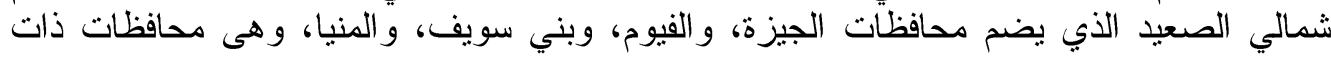

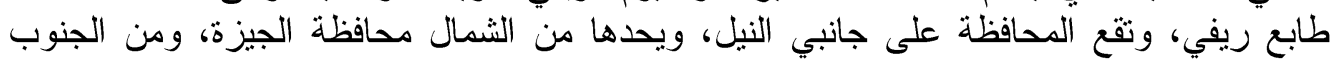

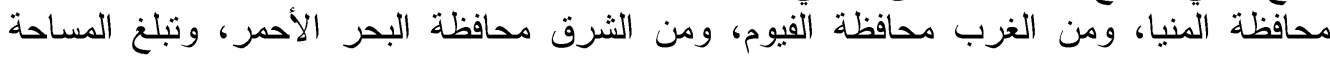

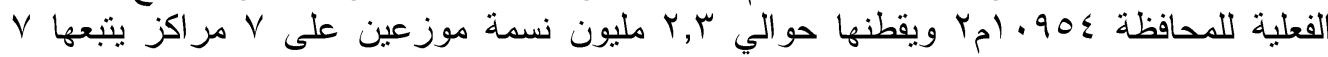

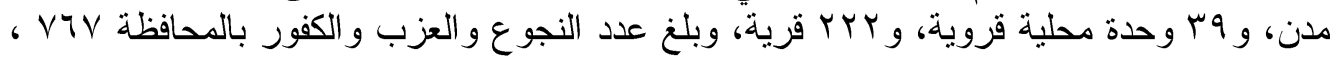

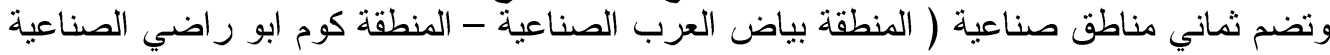

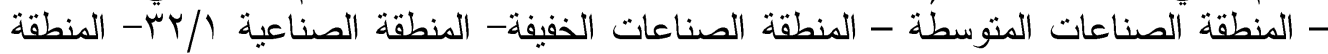

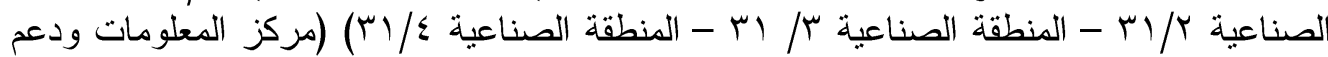

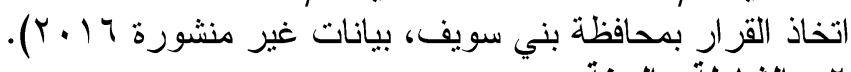

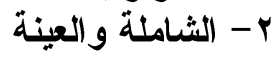

تتمثل شاملة الدراسة في إجمالي عدد الريفيين العاملين بقطاع الصناعات الغذائية

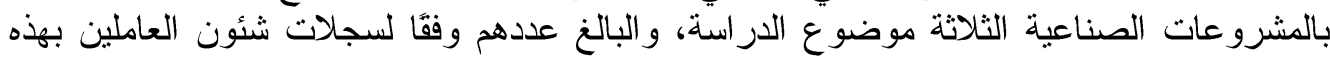

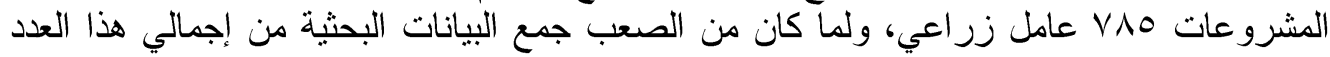

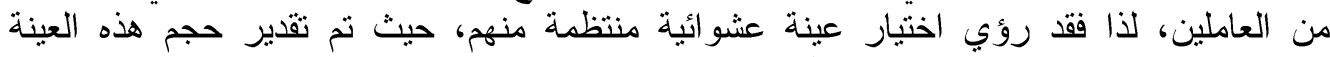

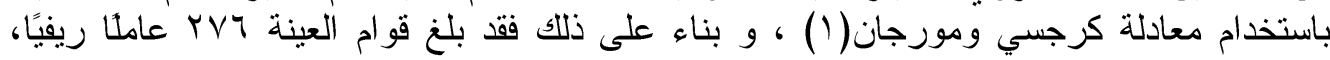

Fayoum J. Agric. Res. \& Dev., Vol. r r, No. r, July, ґ. I^ 
$\varepsilon$

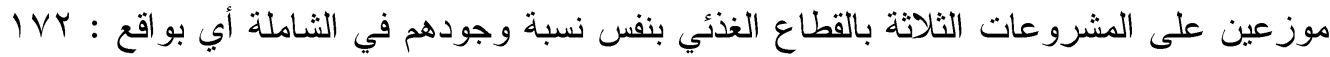

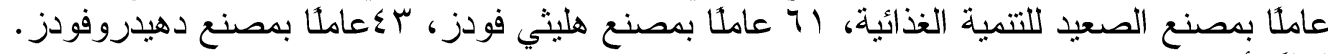
ثالثاً: أدوات جمع البيانات

تم استخدام الاستبيان بالمقابلة الشخصية بوصفها أداةً رئيسية لجمع البيانات البحثية، حيث تم تصميم صحيفتي استبيان الأولى: خاصة بالريفيين العاملين بقطاع الصناعات الغذائية، و الثانية: خاصة بالزر اع التقليديين ولقد تم عمل اختبار مبدئي (pre-test) لبنود صحيفتي الاستبيان

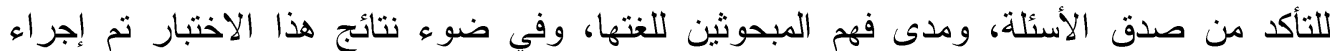
التعديلات اللازمة، وثم صباغة صحيفتي الاستبيان في صورتهما النهائية.

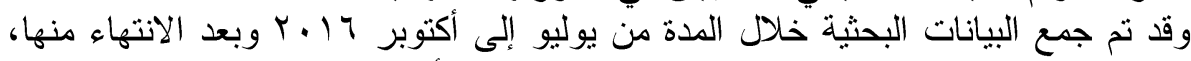
تم جمع البيانات، ومراجعتها، وتصميم دليل لترميزها، وعلى أساسه تم تفريغ البيانات يدوياك، و إدخالها إلى الحاسب الآلى لتحليلها بالاستعانة بالبرنامج الإحصائي (spsS-VY). رابعًا: أساليب التحليل الإحصائي

أستخدمت أساليب ومقاييس أحصائية مختلفة لتحقيق أهداف الدر اسة ، و اختبار فروضها، حيث استخدم اختبار مربع (Chi square test) لاختبار فروض الار اسة الخاصة بعلاقة متغيرات

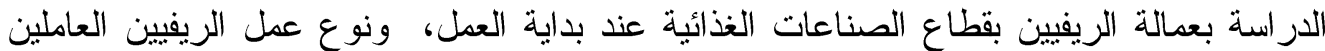
بقطاع الصناعات الغذائية، وقد رؤي استخدام هذا الأسلوب الأحصائي نظرًا لملأئكته لمتغيرات

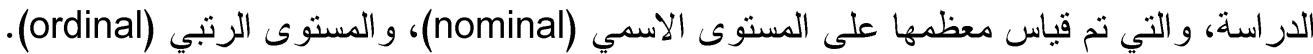

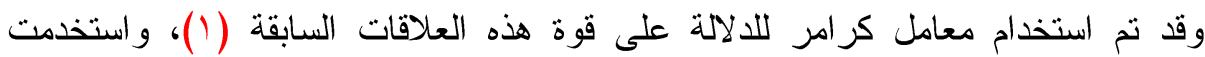
التوزيعات التكرارية، و النسب المئوية، والمتوسطات، و المدى و الانحر اف المعياري في عرضه، هونات ووصف متغير ات الدر اسة.

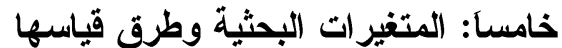

يتضمن هذا الجزء من الدراسة التعاريف الإجرائية، وكيفية قياس المتغير ات البهات البحثية المتعلقة بكل من عمالة الريفيين بقطاع الصناعات الغذائية، و بأعمار هم عند بداية العمل، وبنو، وكلية العمل، وذلك

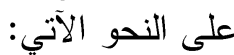

- المتغير ات المتثعقة بعمالة الريفيين بقطاع الصناعات الغذائية

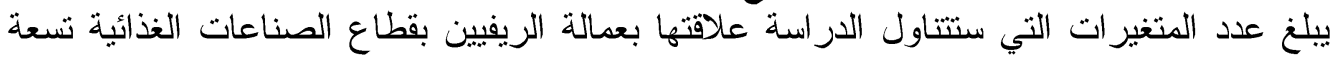

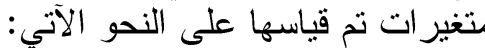

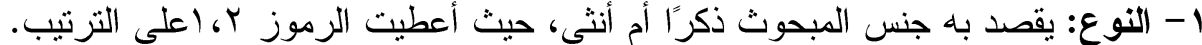
r-العمر: يقصد به عدد السنوات التي مرت على المبحوث منذ ميلاده وحتى وقت جمع البيانات، وذلك لأقرب سنة ميلادية.

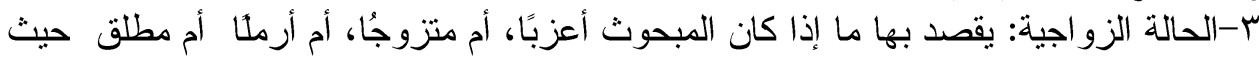

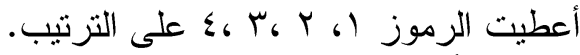
ع - النشأة: يقصد بها ما إذا كان المبحوث من أصل ريفي أم حضري، حيث اعطيت الرموز r ب على الترثي ه - المستوى التعليمي: يقصد به ما إذا كان المبحوث حاصل على شهادة دراسة أم غير حاصل

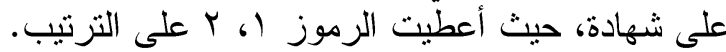

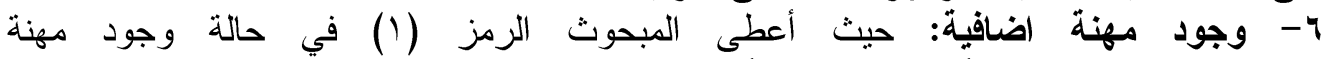

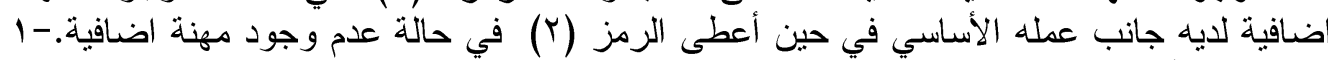
- V حجم الأسرة: يقصد بها عدد أفر أد أسرة المبحوث، و الذين يشتركون في وحدة معيشية مشتركة.

Fayoum J. Agric. Res. \& Dev., Vol. "rr, No. r, July, r. 11 
$\varepsilon 1$

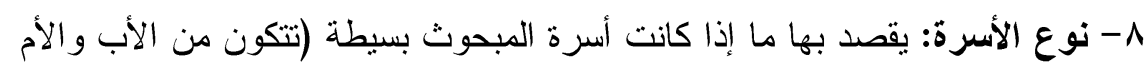
و الأبناء فقط)، أم أسرة ممتدة (تشتمل على أكثر من جيل بخلاف الأب و الأم و الأبناء)، حيث أعطيت

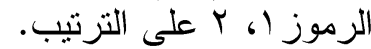
9- مستوى المعيشة: يقصد به الثرتئ تقدير المبحوث الذاتي لمستوى معيشة أفراد أسرته منخفضا كان أم

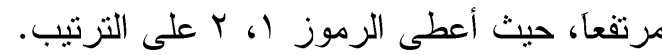

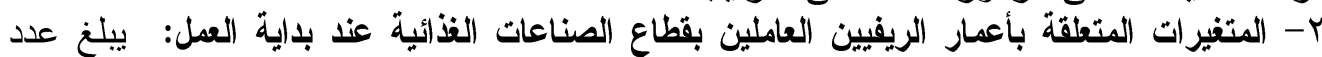

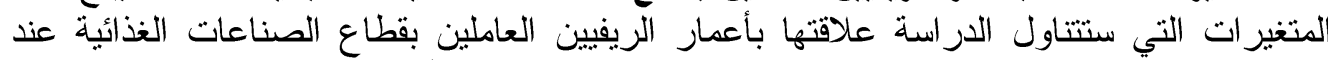

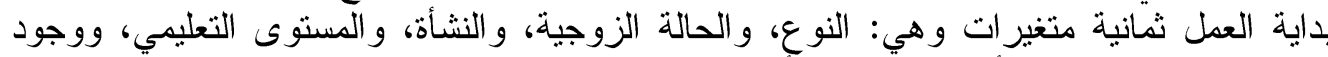

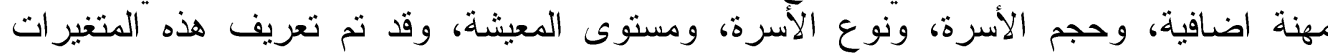

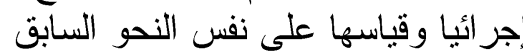
ب-المتغير ات المتعلقة بنوع عمل الريفين العاملين بقطاع الصناعات الغذائية : يبلغ عدد المتغيرات

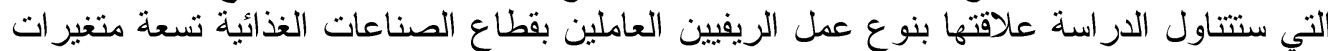

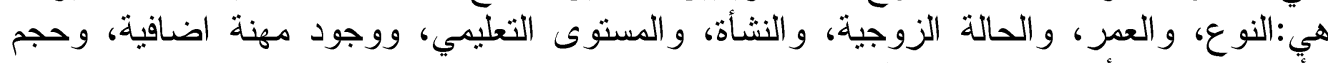

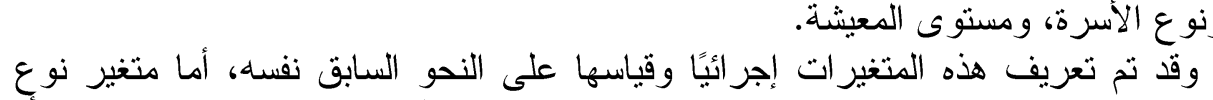

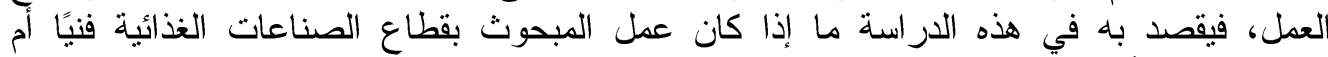

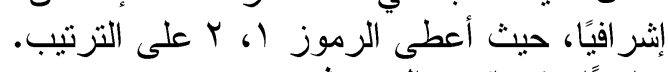

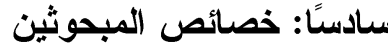

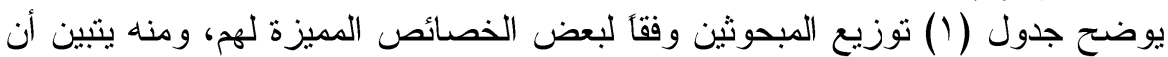

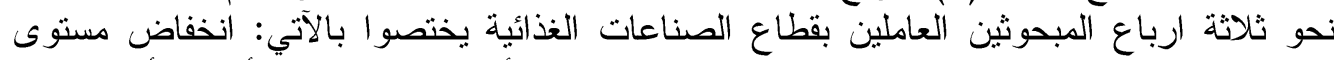

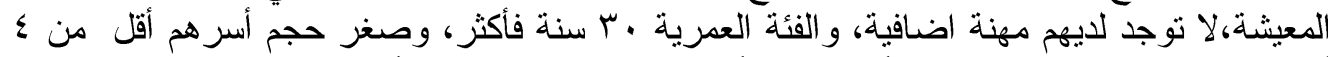

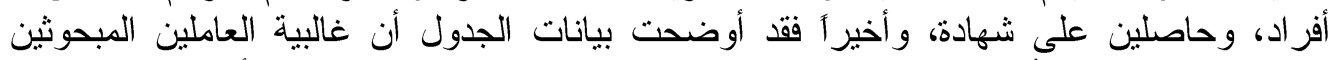

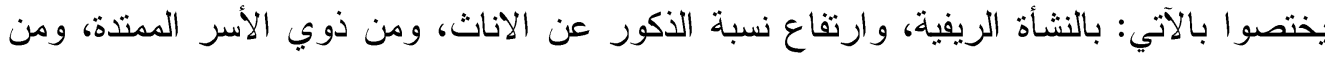
فئة المتزوجين. جدول (1): توزيع المبحوثين بعينتي الار اسة وفقاً لبعض المتغيرات المميزة لهن.

\begin{tabular}{|c|c|c|c|c|c|}
\hline \multicolumn{2}{|c|}{ Y Y } & \multirow{2}{*}{ المتغيرات } & \multicolumn{2}{|c|}{$Y V Y=\dot{U}$} & \multirow{2}{*}{ المتغيرات } \\
\hline$\%$ & عدد & & $\%$ & عدد & \\
\hline $\begin{array}{l}r, 9 \\
9 r, 1\end{array}$ & $\begin{array}{l}\text { Yr } \\
\text { YOS }\end{array}$ & 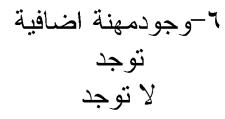 & $\begin{array}{l}\mathcal{O V , T} \\
\Sigma Y, \varepsilon\end{array}$ & $\begin{array}{l}109 \\
111\end{array}$ & أن النوع : \\
\hline $\begin{array}{l}00,1 \\
\leq \varepsilon, 9\end{array}$ & $\begin{array}{l}10 Y \\
1 Y \varepsilon\end{array}$ & 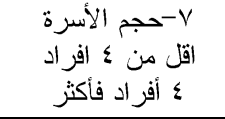 & 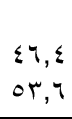 & $\begin{array}{l}1 Y 1 \\
1 \leq 1\end{array}$ & 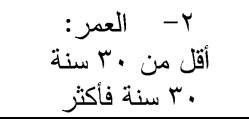 \\
\hline $\begin{array}{l}70, T \\
r \leq, \leq \\
\end{array}$ & $\begin{array}{l}111 \\
90\end{array}$ & ^-فنوع الاسرة & $\begin{array}{l}r 0, r \\
\varepsilon r, \Lambda\end{array}$ & $\begin{array}{l}11 . \\
97\end{array}$ & 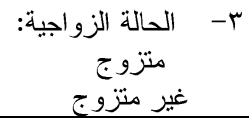 \\
\hline $\begin{array}{l}9 V, 1 \\
r, 9\end{array}$ & $\begin{array}{c}\mu 4 \\
\wedge\end{array}$ & 9-مستوى المعيشة & $\begin{array}{l}9 \leq, r \\
0,1\end{array}$ & $\begin{array}{l}47 . \\
17\end{array}$ & ع- ريفي النشأة \\
\hline & & & $\begin{array}{l}r Y, \Lambda \\
V r, r\end{array}$ & $\begin{array}{l}Y \varepsilon \\
Y \cdot r\end{array}$ & 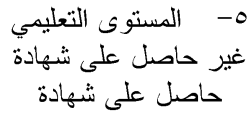 \\
\hline
\end{tabular}

Fayoum J. Agric. Res. \& Dev., Vol. rr, No. ', July, r. IA 
يتضمن هذا عرضيًا لنتائج الدراسة المتعلقة بطبيعة وظروف وعمل الريفيين بقطاع

$$
\text { النتائج البحثية }
$$

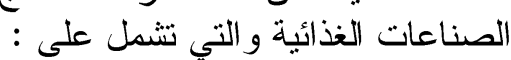

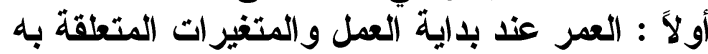

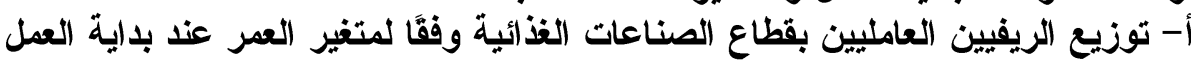

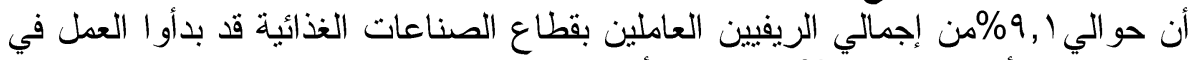

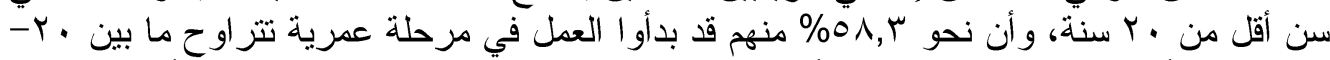

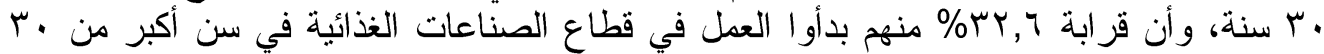

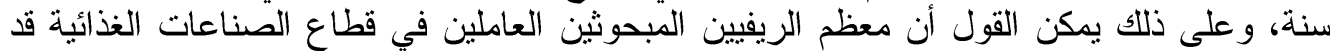

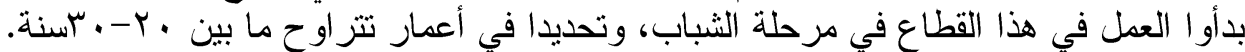

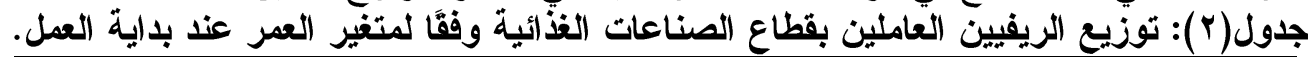

\begin{tabular}{|c|c|c|}
\hline النسبة المئوية & العداد & العمر عند بداية العمل \\
\hline 9,1 & ro & (أقل من • T سنةة) \\
\hline $0 \wedge, \Gamma$ & 171 & ( $)$ \\
\hline$r Y, T$ & 9. & ( أكبر من ·r سنة) \\
\hline $1 \ldots$ & rVY & الإجمالي \\
\hline
\end{tabular}

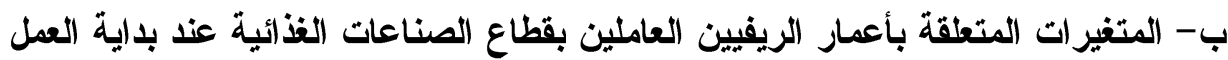

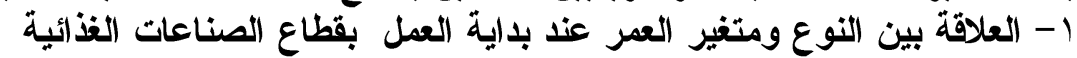

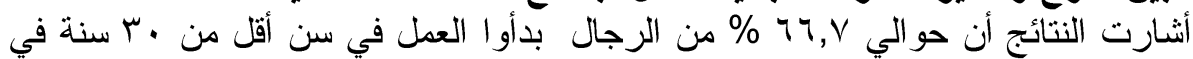

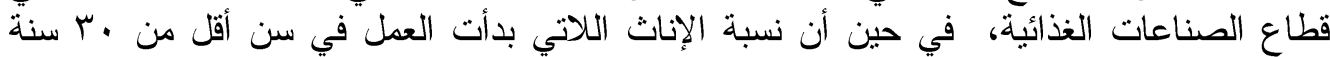

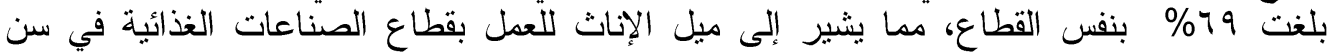

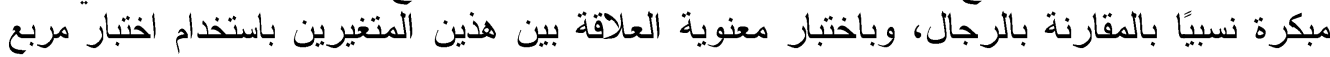

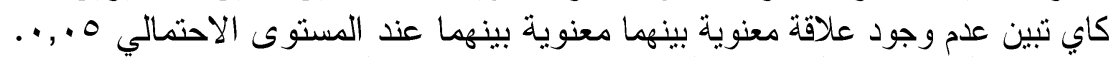

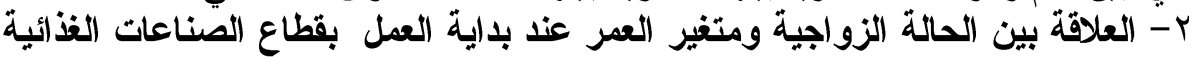

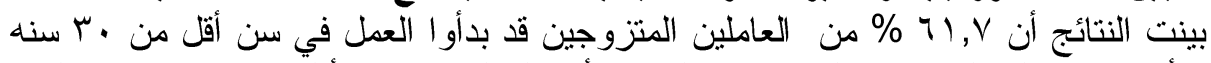

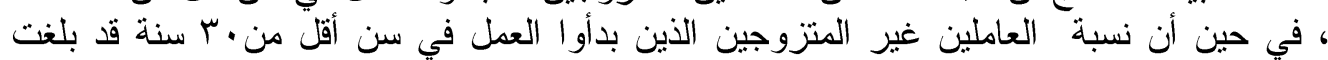
\%VA, 1

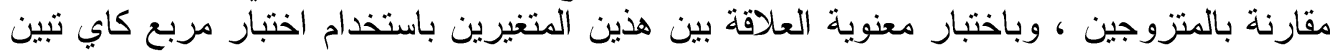

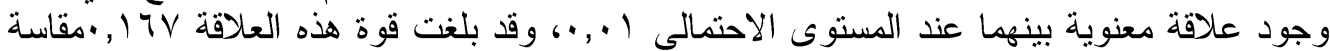

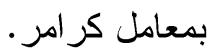

ب- العلاقة بين النشأه ومتغير العمر عند باية العمل بقطاع الصناعات الغذائية

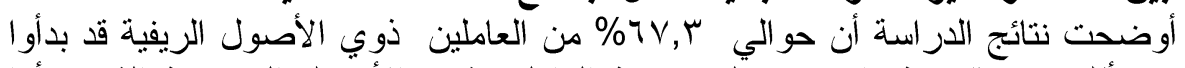

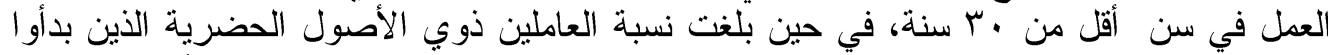

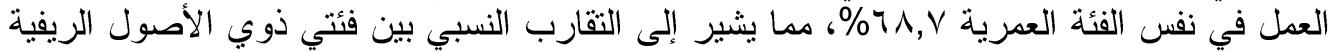

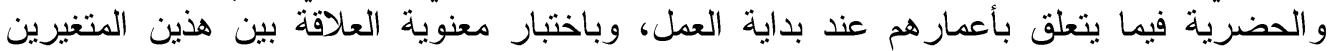

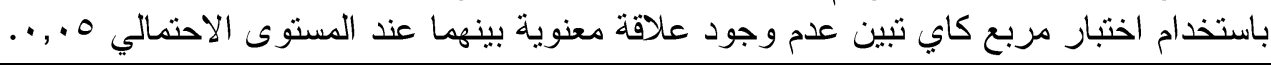

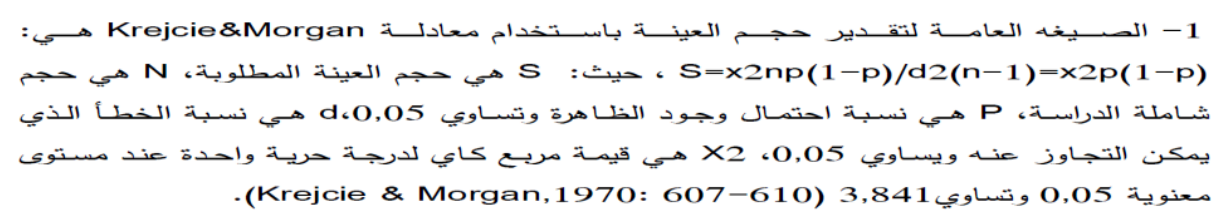

Fayoum J. Agric. Res. \& Dev., Vol. rr, No. ', July, r. IA 
ع- العلاقة بين المستوى التعليمي ومتغير العمر عند بداية العمل بقطاع الصناعات الغذائية

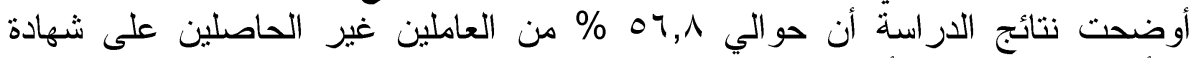

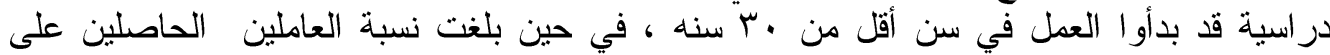

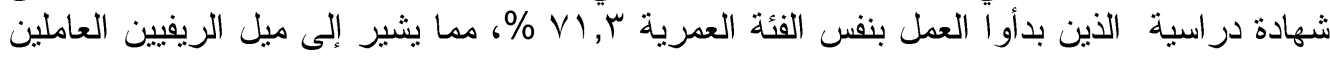

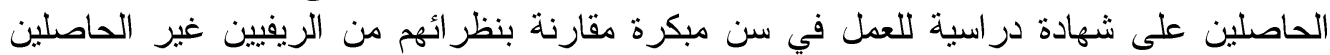

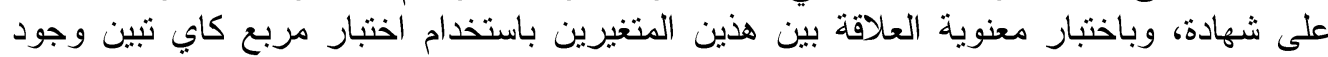

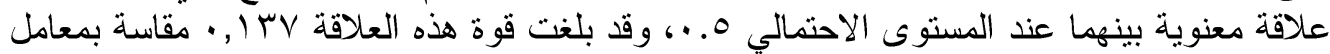

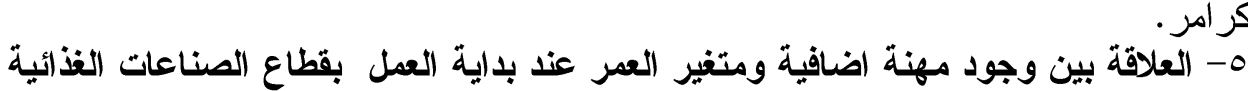

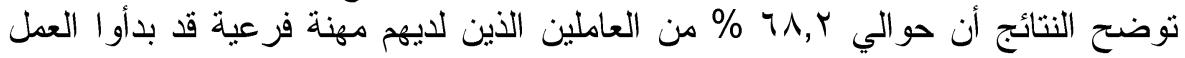

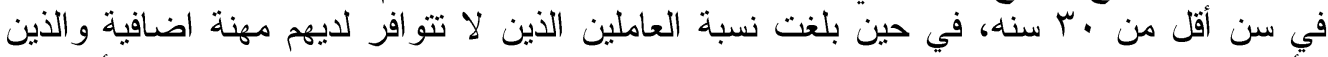

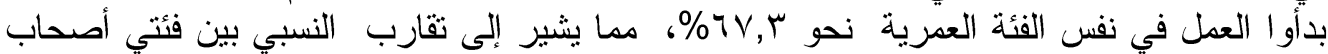

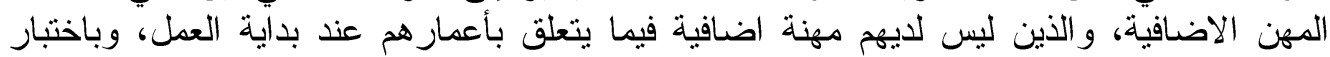

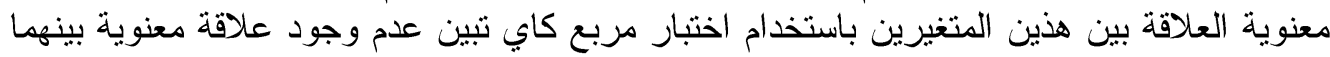

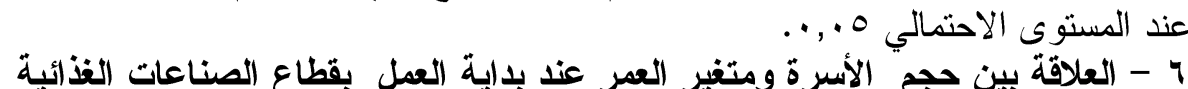

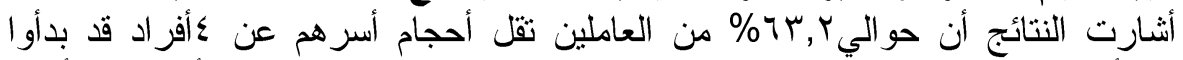

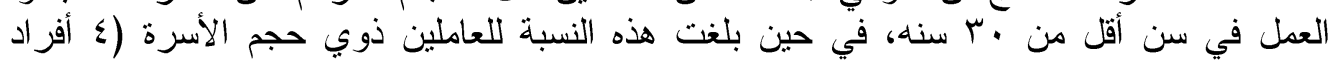

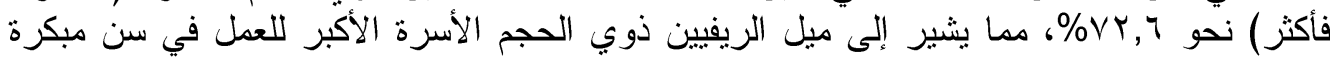

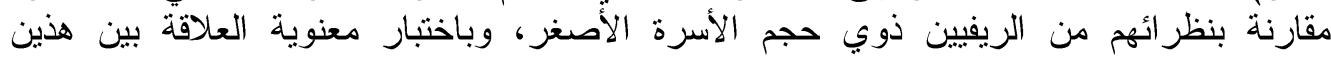

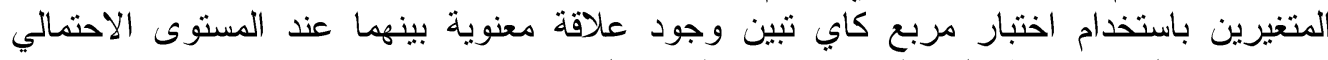

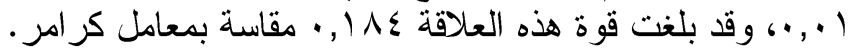

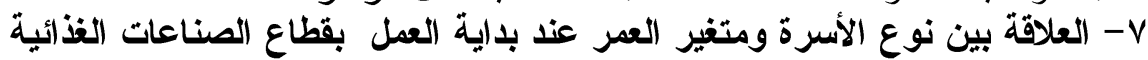

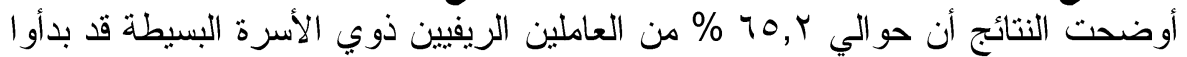

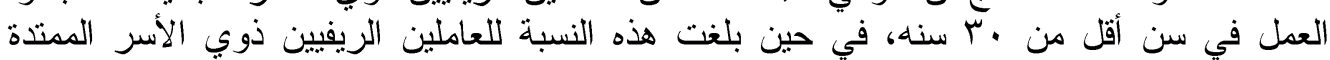

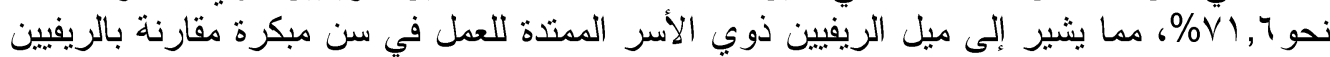

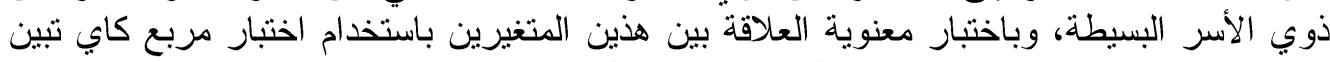

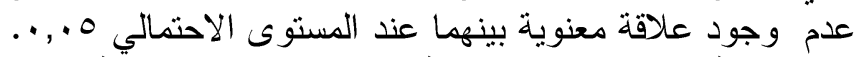

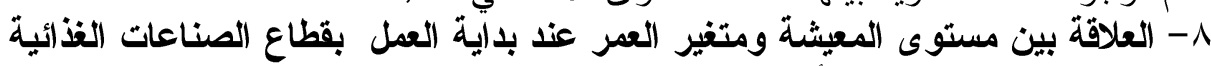

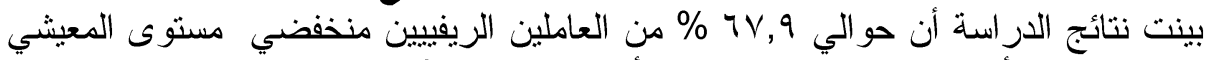

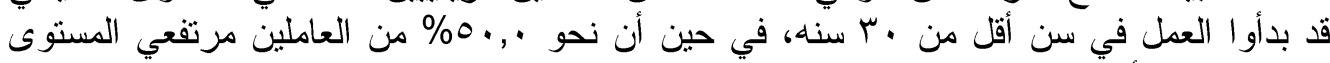

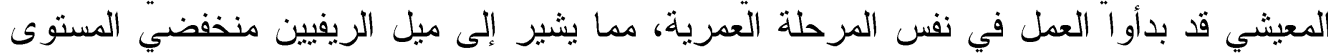

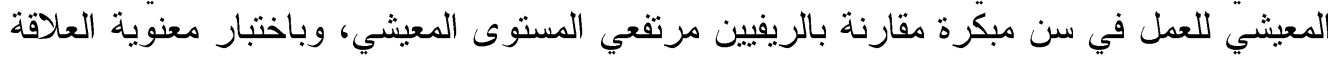

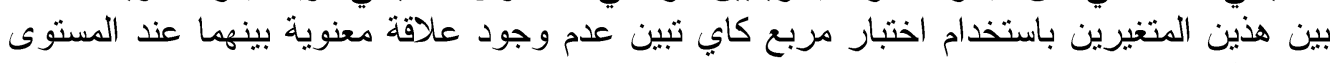

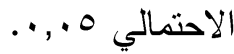

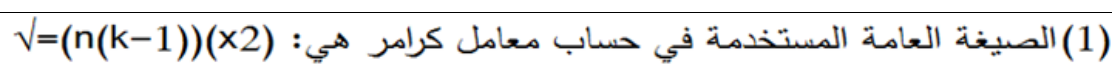

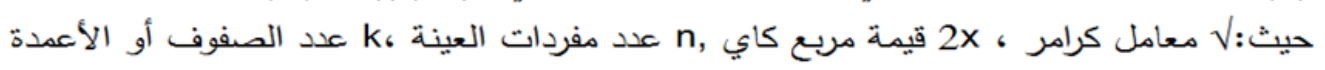

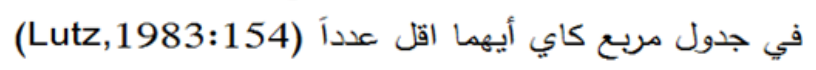

Fayoum J. Agric. Res. \& Dev., Vol. r r, No. r, July, ґ. I^ 
$\varepsilon \varepsilon$

بناء على ما سبق، وفي ضوء نتائج اختبار مربع كاي، يتبين الآتي :

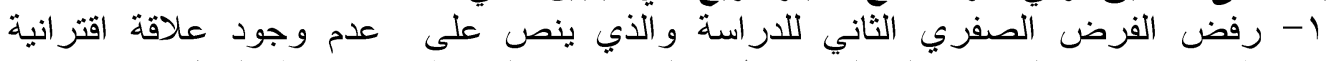

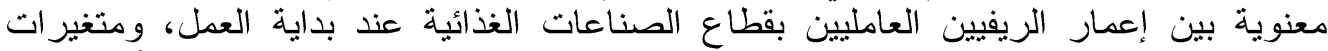

الدر اسة)، وذلك فيما يتعلق بمتغير ات:(الحالة الزو اجية، و المستوى التعليمي، وحجم الأسرة). r- عدم امكانية رفض الفرض الصفري الثاني للار اسة فيما يتعلق بباقي المتغيرات المدروسة

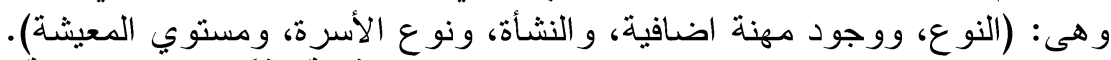

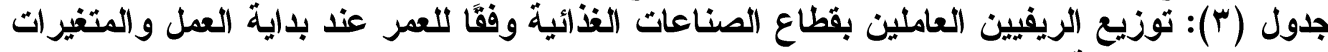
المتعلقة به.

\begin{tabular}{|c|c|c|c|c|c|c|c|}
\hline \multicolumn{7}{|c|}{ العمر عند بداية العمل } & \multirow{3}{*}{ المتغير } \\
\hline \multicolumn{2}{|c|}{ الجملة } & \multicolumn{2}{|c|}{ • •اسنة فأكثر } & \multicolumn{3}{|c|}{ أقلّ من ·ساسنة } & \\
\hline$\%$ & عدد & $\%$ & عدد & $\%$ & \multicolumn{2}{|r|}{ عدد } & \\
\hline \multicolumn{8}{|c|}{ ا 1 النوع } \\
\hline $1 \ldots$ & 109 & $r \leqslant, \cdot$ & $0 \leqslant$ & $74, \cdot$ & \multicolumn{2}{|r|}{1.0} & ذكور \\
\hline $1 \ldots$ & $11 \mathrm{~V}$ & $r, \cdot$. & $r 4$ & $79, \cdot$ & \multicolumn{2}{|r|}{ 1) } & إناث \\
\hline $1 \cdots$ & TVT & TY,T & 9. & $T V, \Sigma$ & \multicolumn{2}{|r|}{114} & الجملة \\
\hline \multicolumn{8}{|c|}{ r-الحالة الزواجية } \\
\hline $1 \ldots$ & 11. & $\mu \wedge, r$ & 79 & $\pi, V$ & \multicolumn{2}{|r|}{111} & متزوج \\
\hline $1 \ldots$ & 97 & $r 1,9$ & YI & $\vee \wedge, 1$ & \multicolumn{2}{|r|}{ vo } & غير متزو ج \\
\hline $1 \ldots$ & YVT & $r r, T$ & 9. & $T V, \varepsilon$ & \multicolumn{2}{|r|}{114} & الجملة \\
\hline \multicolumn{8}{|c|}{ 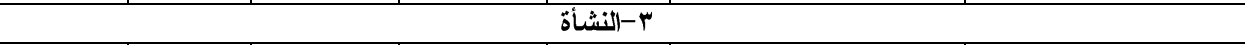 } \\
\hline $1 \ldots$ & Y.. & $r Y, V$ & 10 & $T V, r$ & \multicolumn{2}{|r|}{ IVo } & ريفي \\
\hline $1 \cdots$ & 17 & $r, r$ & 0 & $\checkmark \Lambda, V$ & \multicolumn{2}{|r|}{11} & حضري \\
\hline $1 \ldots$ & TVT & $r Y, T$ & 9. & $T V, \varepsilon$ & \multicolumn{2}{|r|}{117} & الجملة \\
\hline \multicolumn{8}{|c|}{ ع -المستوى التعليمي } \\
\hline $1 \cdots$ & $V \varepsilon$ & $\varepsilon r, r$ & Tr & 04,1 & \multicolumn{2}{|r|}{$\leqslant r$} & غير حاصل على شهادة \\
\hline $1 \ldots$ & $r \cdot r$ & $r \wedge, \Lambda$ & 01 & $v 1, r$ & \multicolumn{2}{|r|}{$1 \leq \varepsilon$} & حاصل على شهادة در اسية \\
\hline $1 \cdots, \cdot$ & rVI & rY,T & 9. & $T V, \Sigma$ & \multicolumn{2}{|r|}{1114} & الجملة \\
\hline \multicolumn{7}{|c|}{ العمر عند بداية العمل } & \multirow{3}{*}{ المتغير } \\
\hline \multicolumn{2}{|c|}{ الجملة } & \multicolumn{3}{|c|}{ • اسسنة فأكثر } & & أقل من · "آ & \\
\hline$\%$ & عدد & & & عدد & $\%$ & عدد & \\
\hline & & & & لد مهنة & -0 & & \\
\hline $1 \ldots$ & YY & & & v & $T \Lambda, r$ & 10 & يوجد \\
\hline $1 \cdots$ & YOS & & & $\Lambda \mu$ & $T V, r$ & $\mid V I$ & لا يوجد \\
\hline $1 \ldots$ & YVY & & & 9. & $T V, \Sigma$ & 1117 & الجملة \\
\hline & & & & مجم الأر & & & \\
\hline $1 \ldots$ & 104 & & & 07 & $T r, r$ & 97 & (أقل من عأفر اد) \\
\hline $1 \ldots$ & $1 Y \varepsilon$ & & & $r \varepsilon$ & $V Y, T$ & 9. & (عأفز اد فأكثر) \\
\hline $1 \ldots$ & YVT & & & 9. & $T V, \Sigma$ & 1117 & الجملة \\
\hline & & & & نوع الأ & & & \\
\hline $1 \ldots$ & 111 & & & $\pi$ & $70, r$ & 111 & بسيطة \\
\hline $1 \ldots$ & 90 & & & $r V$ & 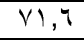 & 71 & ممتدة \\
\hline $1 \ldots$ & TVT & & & 9. & $T V, \Sigma$ & 114 & الجملة \\
\hline & & & & توى الذ & & & \\
\hline $1 \ldots$ & rYA & & & 14 & $T V, q$ & INY & منخفض \\
\hline $1 \cdots$ & $\Lambda$ & & & $\varepsilon$ & $0 \cdot, \cdot$ & $\varepsilon$ & مرتفع \\
\hline $1 \cdots$ & TVT & & & 9. & $T V, \varepsilon$ & 1117 & الجمـلة \\
\hline
\end{tabular}

Fayoum J. Agric. Res. \& Dev., Vol. r r, No. r, July, ץ. I^ 
\&o

جدول (ع): علاقة بعض المتغيرات بالعمر عند باية العمل موضحه بقيم مربع كاي وقيم معامل

\begin{tabular}{|c|c|c|c|}
\hline & & \multicolumn{2}{|c|}{ كر امر. } \\
\hline معامل كر (مر & مربع كاي & المتغير ات & s \\
\hline$\cdot, \cdot r \leq$ & $\cdot, \pi$ & النوع & 1 \\
\hline$\cdot, 17 V$ & $* * \vee, \bigvee \backslash$ & الحاله الزواجية & $r$ \\
\hline$\cdot, \cdots V$ & $\cdot, \cdot 1 \leq$ & النشأة & $r$ \\
\hline $.1 \% \mathrm{~V}$ & $* 0, Y$. & المستوى التعليمي & $\varepsilon$ \\
\hline.,$\ldots 0$ & $\cdot, \cdots V$ & وجود مهنة اضافية & 0 \\
\hline$\cdot, 1 \wedge \varepsilon$ & $* * q, r V$ & حجم الأسرة & 7 \\
\hline., .90 & 1,10 & نوع الأسرة & $\mathrm{V}$ \\
\hline$\cdot, .94$ & r, ro & مستوى المعيشة & $\Lambda$ \\
\hline
\end{tabular}

ثأنياً: نوع العمل و المتغيرات المتعلقة به:

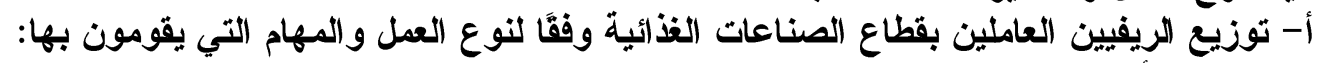

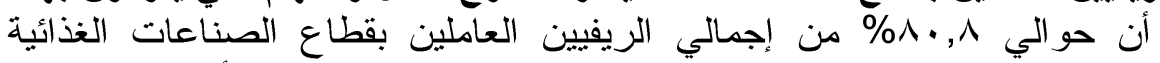

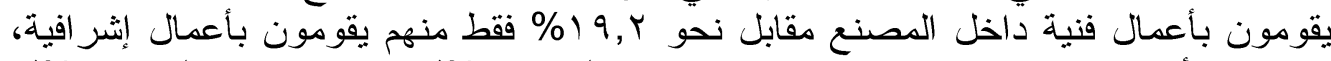

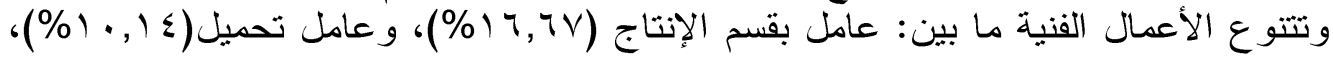

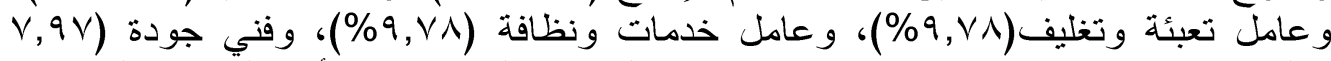

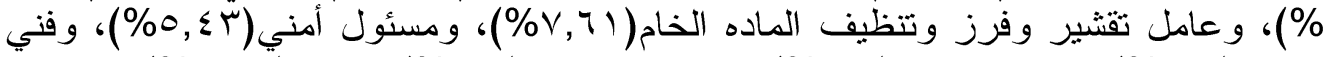

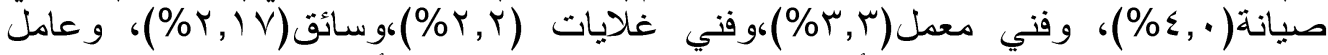

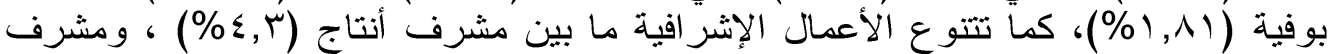

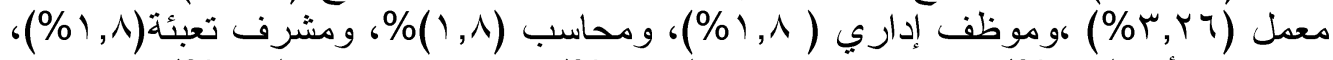

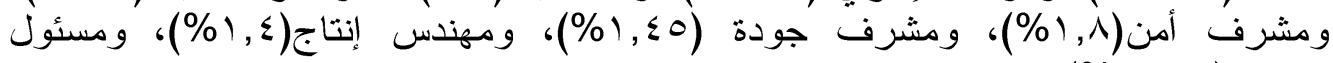

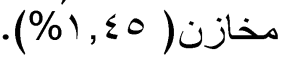

Fayoum J. Agric. Res. \& Dev., Vol. r r, No. r, July, ґ. I^ 
$\varepsilon 7$

جدول( • ) توزيع الريفين بقطاع الصناعات الغذائية وفقًا لنوع العمل والمهام التي يقومون بها.

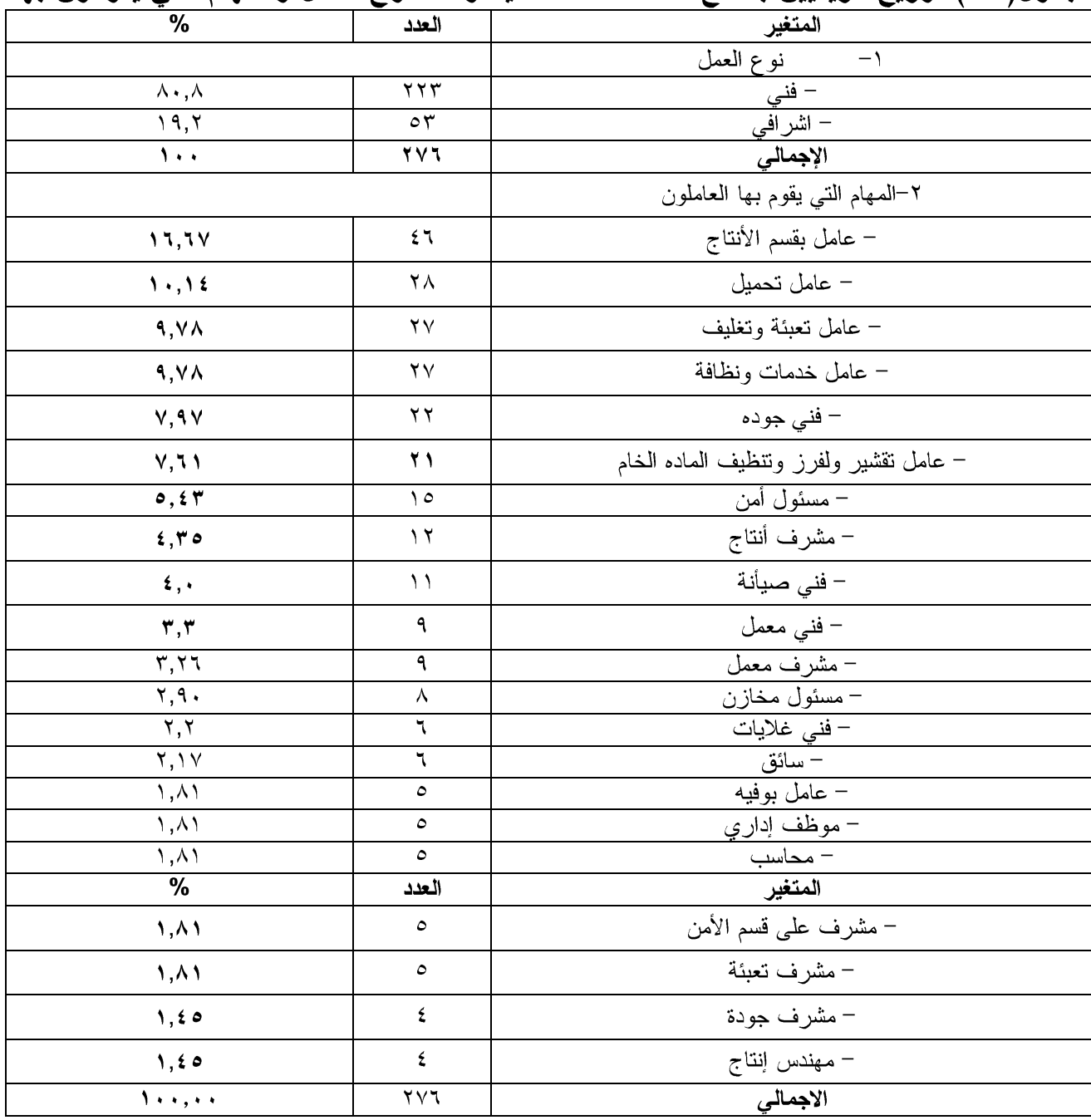

ب- المتغيرات المتعلقة بنوع عمل الريفيين العاملين بقطاع الصناعات الغذائية ا-العلاقة بين النوع ومتغير نوع العمل بقطاع الصناع الصناعات الغذائية:

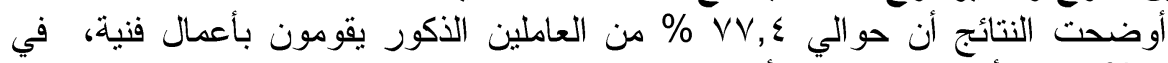

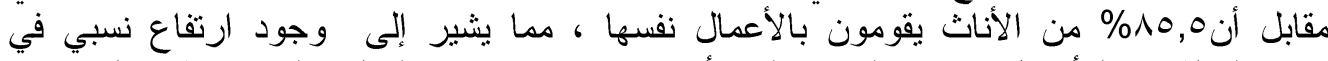

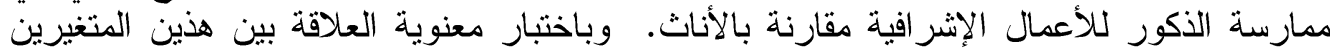

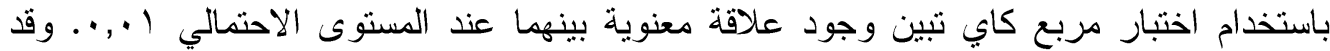

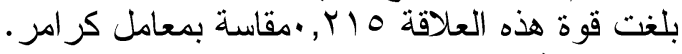

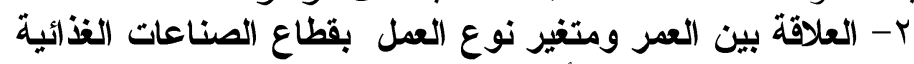

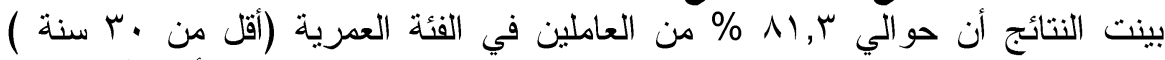

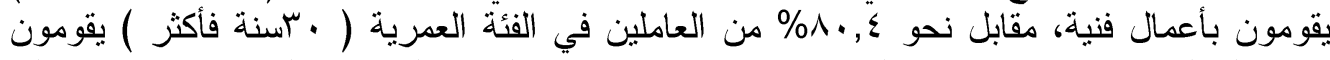
بالاعمال الفنية نفسها، مما يشير إلى وجود تقارب نسبي بين الفئتين العمرثين المدروستين فيما يتعلق

Fayoum J. Agric. Res. \& Dev., Vol. " r r, No. r, July, r. I 1 
بمجال العمل، وباختبار معنوية العلاقة بين هذين المتغيرين باستخدام اختبار مربع كاي تبين عدم

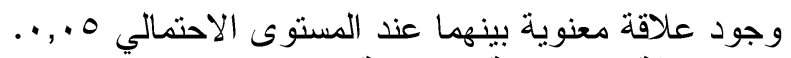

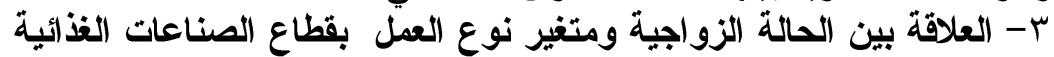

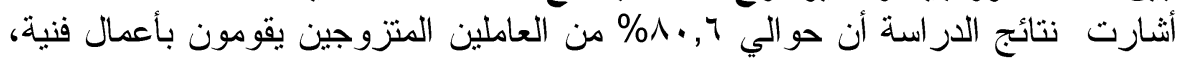

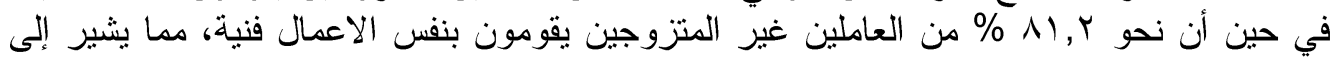

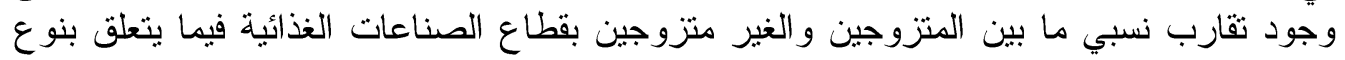

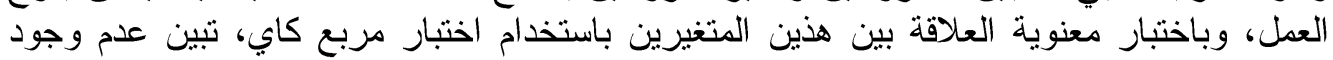
علاقة معنوية بينهما عند المستوى الاحتمالي 0 ., •.

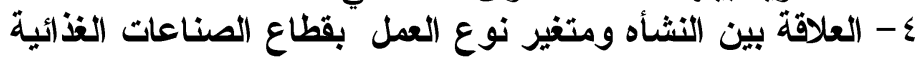

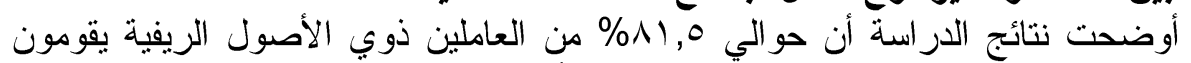

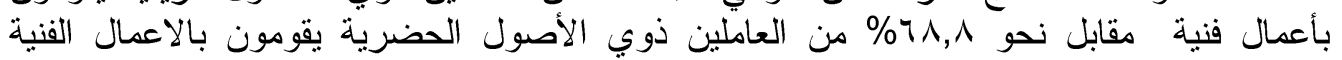

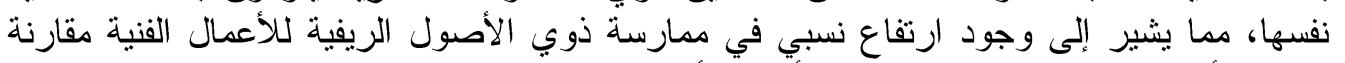

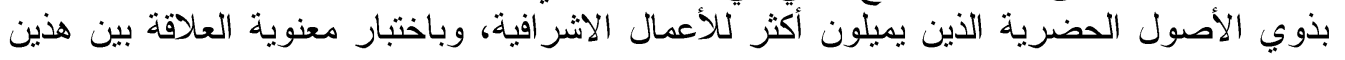

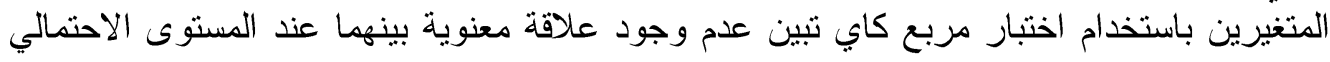

0- التعلاقة بين المستوى التعليمي ومتغير نوع العمل بقطاع الصناعات الغذائية

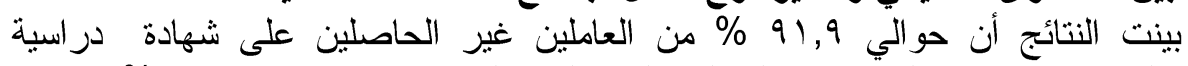

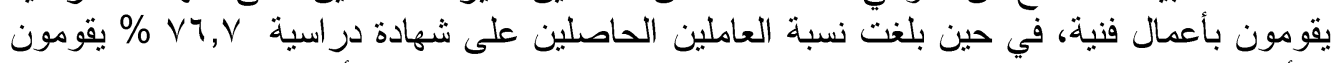

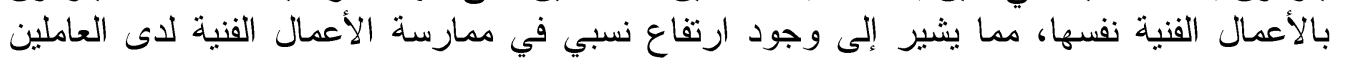

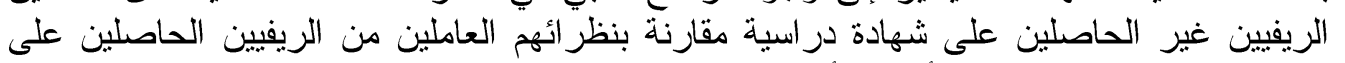

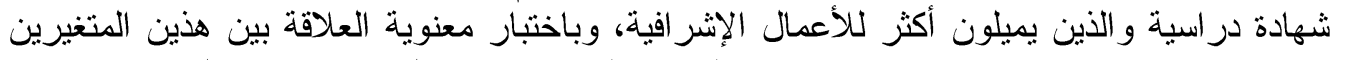

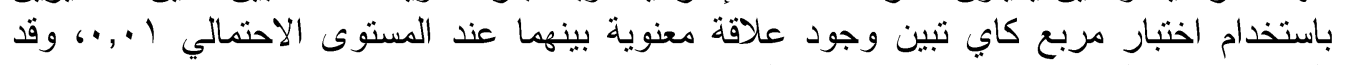

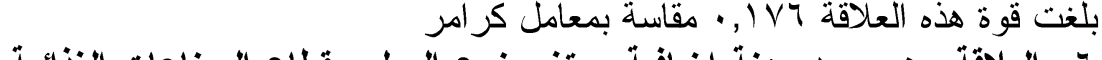

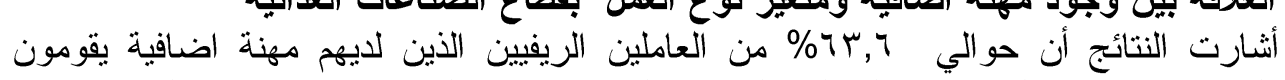

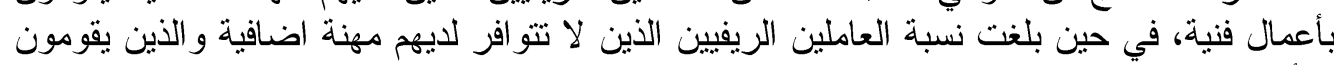

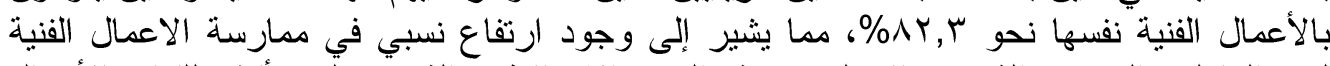

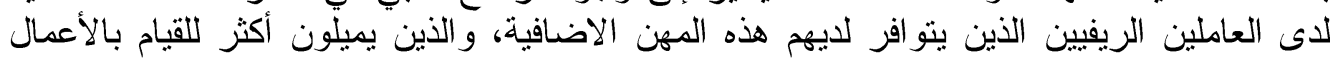

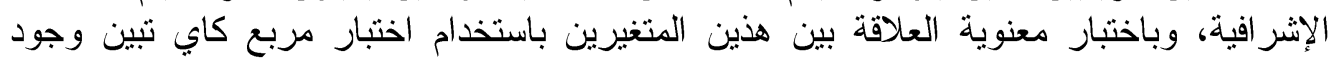

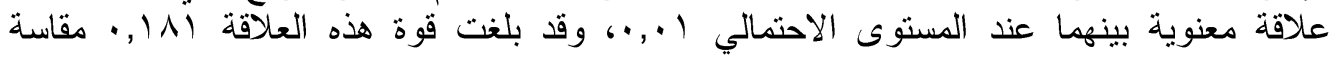

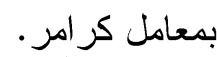

V

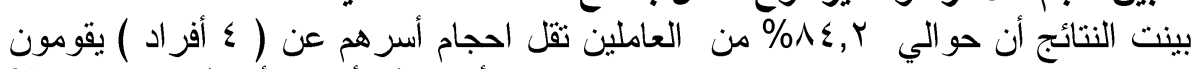

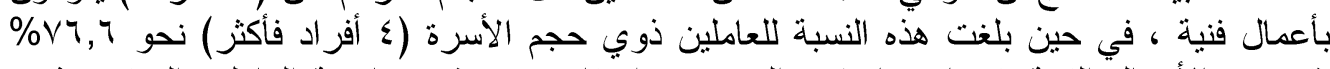

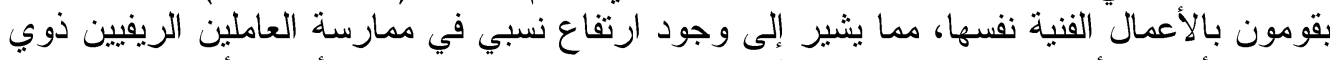

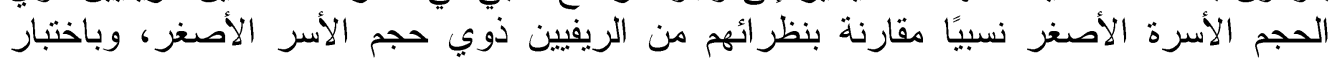

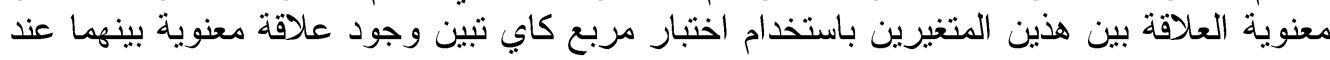

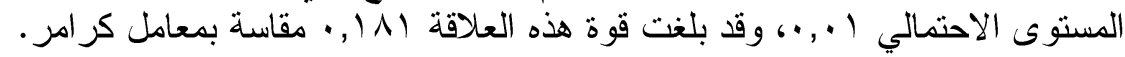

Fayoum J. Agric. Res. \& Dev., Vol. ' r, No. r, July, ץ. I^ 


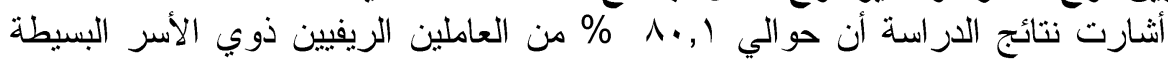

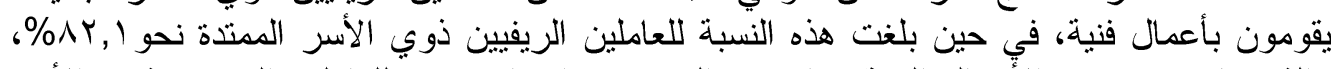

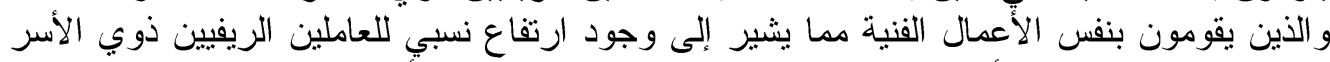

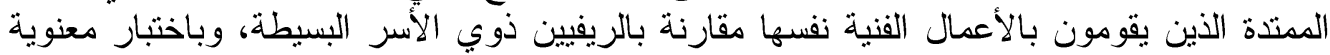

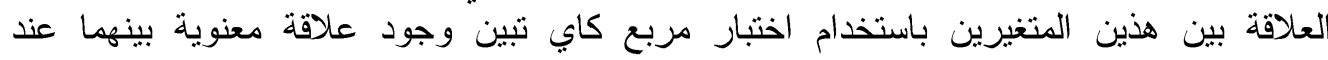

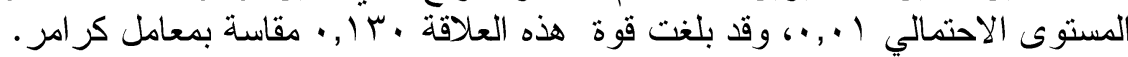

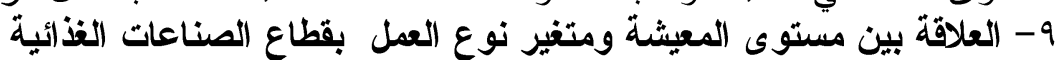

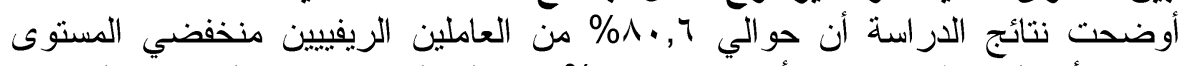

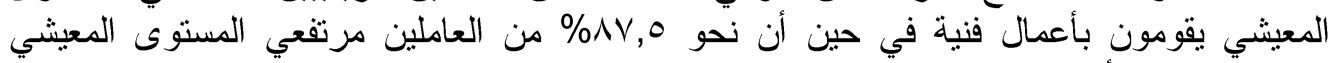

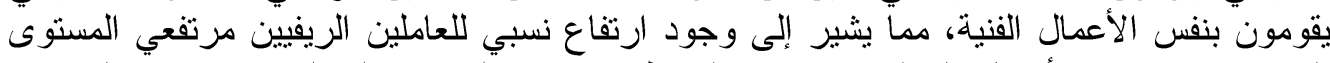

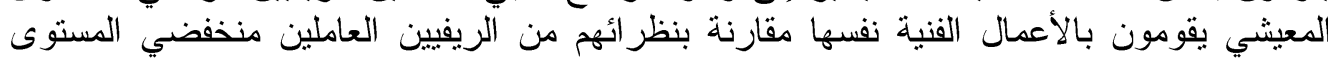

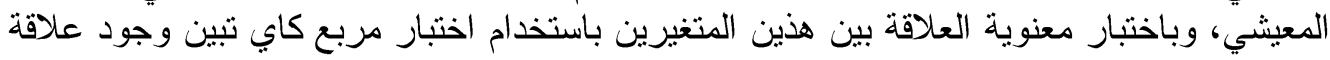

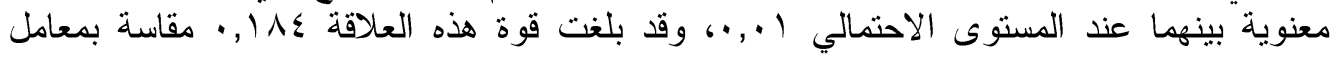

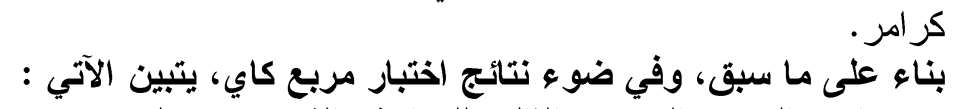

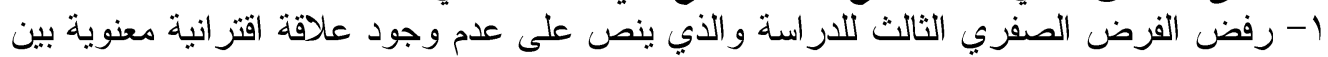

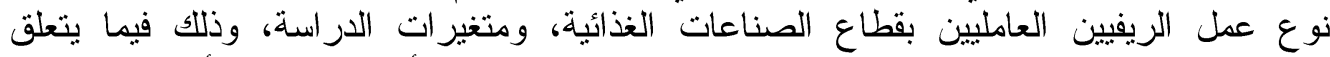

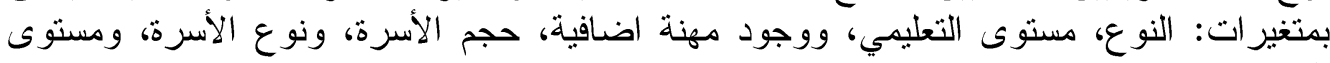

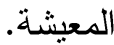
r- عدم امكانية رفض الفرض الصفري الثالث للاراسة فيما يتعلق بباقي المتغيرات المدروسة وهى: العمر ، و الحالة الزو اجية، و النشأة.

Fayoum J. Agric. Res. \& Dev., Vol. 'r, No. r, July, ץ.lı 
$\leq 9$

جدول (†) توزيع الريفيين العاملين بالقطاع الصناعي وفقًا لمتفيرات الاراسة ونوع العمل

\begin{tabular}{|c|c|c|c|c|c|c|}
\hline \multirow{2}{*}{\multicolumn{2}{|c|}{ الجملة }} & \multirow{2}{*}{\multicolumn{2}{|c|}{ إثر افي }} & \multirow{2}{*}{\multicolumn{2}{|c|}{ فني }} & \multirow{3}{*}{ المتغير } \\
\hline & & & & & & \\
\hline$\%$ & عداد & $\%$ & عدد & $\%$ & عدد & \\
\hline \multicolumn{7}{|c|}{ 1 } \\
\hline $1 \ldots$ & 109 & $T Y, T$ & rq & $V Y, \varepsilon$ & IKr & ذكر \\
\hline $1 \ldots$ & $11 \mathrm{~V}$ & $1 \leqslant, 0$ & IV & 10,0 & $1 \ldots$ & أنثى \\
\hline $1 \ldots$ & TVY & $19, r$ & or & $\Lambda \cdot, \wedge$ & TrT & الجملة \\
\hline \multicolumn{7}{|c|}{ r ا-العمر } \\
\hline $1 \ldots$ & $1 Y \Lambda$ & $1 \wedge, \wedge$ & $r \leqslant$ & $\Lambda 1, r$ & 1.5 & أقل من ·"سانة \\
\hline $1 \ldots$ & $1 \leq \Lambda$ & 19,7 & rq & $\Lambda \cdot, \varepsilon$ & 119 & . r سنة فأكثر . \\
\hline $1 \ldots$ & TVY & $19, r$ & or & $\wedge \cdot, \wedge$ & Trt & الجملة \\
\hline \multicolumn{7}{|c|}{ r-الحالة الزواجية } \\
\hline $1 \cdots$ & 11. & $19, \varepsilon$ & ro & $\Lambda \cdot, \uparrow$ & $1 \leq 0$ & متزوج \\
\hline $1 \cdots$ & 97 & $i \wedge, \wedge$ & 11 & $\Lambda, Y$ & $\vee \wedge$ & غير متزوج \\
\hline $1 \ldots$ & YVY & $19, r$ & or & $\Lambda \cdot, \wedge$ & TYT & الجملة \\
\hline \multicolumn{7}{|c|}{ ع-النشأة } \\
\hline $1 \ldots$ & ז. & 11,0 & $\varepsilon \wedge$ & $\Lambda 1,0$ & YIT & ريفي \\
\hline $1 \ldots$ & 17 & $r, r$ & 0 & $\lceil\Lambda, \wedge$ & 11 & حضري \\
\hline $1 \ldots$ & TVY & $19, r$ & or & $\Lambda \cdot, \wedge$ & TYT & الجملة \\
\hline \multicolumn{2}{|c|}{ الجملة } & \multicolumn{2}{|c|}{ إشر افي } & & & \multirow{2}{*}{ المتغير } \\
\hline$\%$ & عدد & $\%$ & عدد & $\%$ & عدد & \\
\hline \multicolumn{7}{|c|}{ ه-المستوى التعليمي } \\
\hline $1 \cdots$ & $V \varepsilon$ & $\Lambda, 1$ & 7 & 91,9 & 71 & غير حاصل على شهادة \\
\hline $1 \ldots$ & $r \cdot r$ & $r r, r$ & $\varepsilon V$ & $V \Psi, V$ & 100 & حاصل على شهادة متوسطه \\
\hline $1 \ldots$ & YVY & 9,1 & or & $\Lambda \cdot, \wedge$ & TYT & الجملة \\
\hline & & & & & & ه- وجود مهنة اضافية \\
\hline $1 \ldots$ & YY & rч, ६ & $\Lambda$ & $7 r, 4$ & $1 \varepsilon$ & يوجد \\
\hline $1 \cdots$ & Yos & $I V, V$ & $\leqslant 0$ & $\Lambda Y, r$ & $r .9$ & لا يوجد \\
\hline $1 \cdots$ & YVY & $19, r$ & or & $\Lambda \cdot, \wedge$ & TYT & الجملة \\
\hline \multicolumn{7}{|c|}{ צ-حجم الأسرة } \\
\hline $1 \ldots$ & $10 Y$ & 10,1 & $Y \leq$ & $\Lambda \varepsilon, Y$ & IYA & (أقل من عأفر اد) \\
\hline $1 \ldots$ & 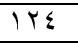 & $r \Psi, \varepsilon$ & rq & $V Y, 7$ & 90 & (ع أفر اد فأكثر) \\
\hline $1 \ldots$ & YVY & $19, r$ & or & $\Lambda \cdot, \wedge$ & TrT & 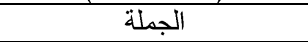 \\
\hline \multicolumn{7}{|c|}{ V - نوع الأسرة } \\
\hline $1 \ldots$ & 111 & 19,9 & my & $\wedge \cdot, 1$ & $1 \leq 0$ & بسيطة \\
\hline $1 \ldots$ & 90 & 17,9 & IV & $\Lambda Y, 1$ & $\vee \wedge$ & ممتدة \\
\hline $1 \ldots$ & YVY & $19, r$ & or & $\Lambda \cdot, \wedge$ & TrT & الجملة \\
\hline \multicolumn{2}{|c|}{ الجملة } & \multicolumn{2}{|c|}{ إثر افي } & & & \multirow{2}{*}{ المتغير } \\
\hline$\%$ & عدد & $\%$ & عدد & $\%$ & عدد & \\
\hline \multicolumn{7}{|c|}{ 1- مستوى المعيشة } \\
\hline $1 \ldots$ & $r \checkmark \Lambda$ & $19, \varepsilon$ & or & $\Lambda \cdot, 7$ & Y1T & منخفض \\
\hline $1 \ldots$ & $\Lambda$ & $1 Y, 0$ & 1 & $\Lambda \vee, 0$ & $V$ & مرتفع \\
\hline $1 \ldots$ & YVI & $19, r$ & or & $\wedge \cdot, \wedge$ & YYT & الجملة \\
\hline
\end{tabular}

Fayoum J. Agric. Res. \& Dev., Vol. rr, No. ', July, r. IA 
๑.

جدول(V): علاقة بعض المتغيرات بنوع العمل( فني- إثر افي)موضحة بقيم مربع كاي وقيم معامل

\begin{tabular}{|c|c|c|c|}
\hline & & \multicolumn{2}{|c|}{ كر امر. } \\
\hline معامل كر امر & مربع كاي & المتغير ات & p \\
\hline$\cdot, Y 10$ & $* * I Y, V \nearrow$ & النوع & 1 \\
\hline$\cdot, .0 Y$ & $\cdot, V \circ V$ & العمر & $r$ \\
\hline$\cdot, \wedge$. & 1,71 & الحاله الزواجية & $r$ \\
\hline$\cdot, \Lambda Y$ & I, AV & النشأة & $\varepsilon$ \\
\hline$\cdot, 1 \vee 7$ & $* * \wedge, 09$ & المستوى التعليمي & 0 \\
\hline$\cdot, 1 \vee \varepsilon$ & $* * \wedge, \Gamma \xi$ & وجود مهنة اضافية & 7 \\
\hline$\cdot,|\wedge|$ & $* * 9, \cdot 7$ & حجم الأسرة & V \\
\hline$\cdot, 1 T$ & $* * \varepsilon, 7 \leq 1$ & نوع الأسرة & $\Lambda$ \\
\hline$\cdot, 1 \wedge \varepsilon$ & $* * q, r \leqslant$ & مستوى المعيشة & 9 \\
\hline
\end{tabular}

ثالثاً: طبيعة عمل الريفيين العاملين بقطاع الصناعات الغذائية والظروف المحبطة به

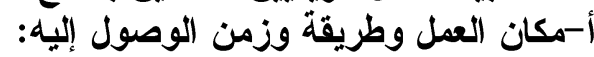

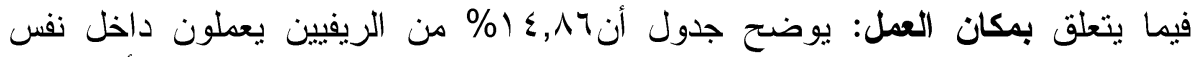

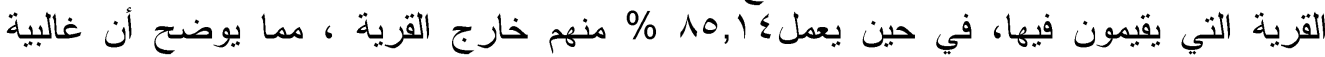

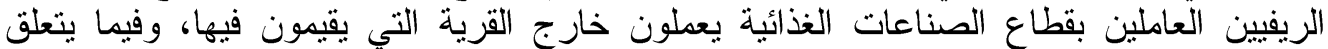

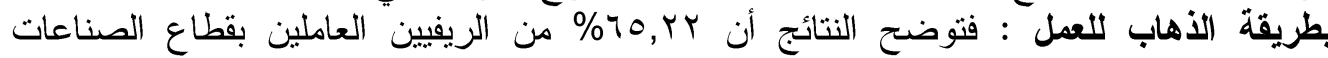

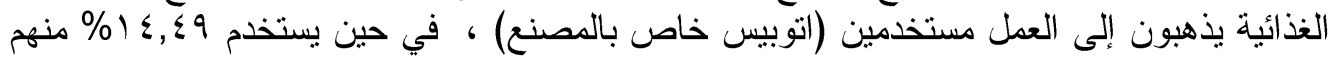

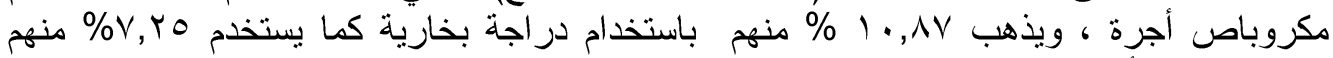

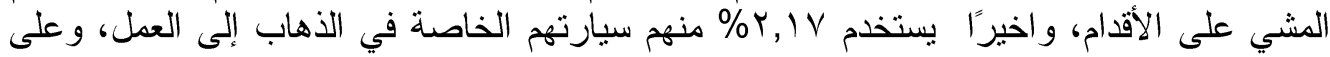

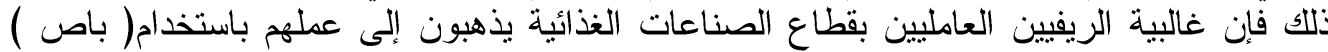

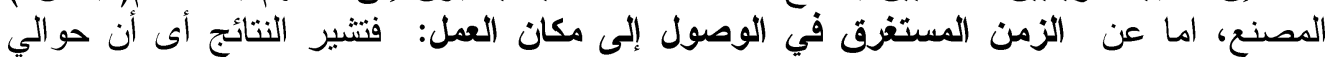

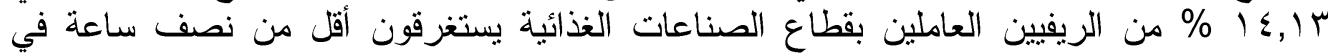

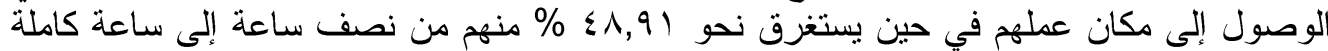

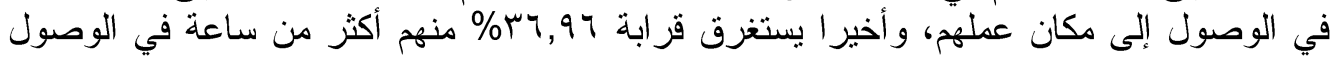

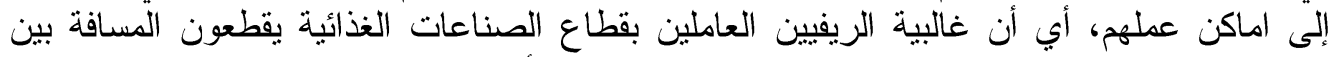

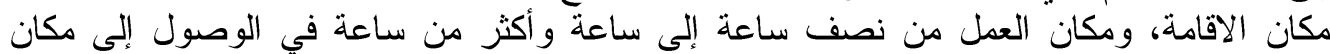

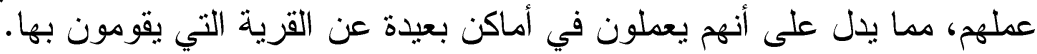

Fayoum J. Agric. Res. \& Dev., Vol. "r, No. r, July, r. I^ 
01

جدول ( ^ ) توزيع للريفيين العاملين بقاع الصناعات الغذائية وفقًا لمكان العمل وطريقة الأهاب

\begin{tabular}{|c|c|c|}
\hline$\%$ & 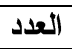 & المتغير \\
\hline \multicolumn{3}{|c|}{ 1- مكان العمل } \\
\hline $1 \varepsilon, \wedge 7$ & §1 & داخل القرية التي يقيم فيها العامل \\
\hline$\wedge 0,1 \leqslant$ & rmo & خارج القرية التي يقيم فيها العامل \\
\hline $1 \cdots, \cdots$ & YVT & الإجمالي \\
\hline$\%$ & العدد & المتغير \\
\hline \multicolumn{3}{|c|}{ r بطريقة الذهاب للعمل } \\
\hline $70, Y Y$ & 11. & 1- اتوبيس خاص بالمصنع \\
\hline $1 \leqslant, \leqslant 9$ & $\varepsilon$. & r- مكروباص أجرة \\
\hline $1 \cdot, \wedge \vee$ & $r$. & ســر اجة بخارية \\
\hline$V, Y_{O}$ & $r \cdot$ & ـ- مشي على الاقدام \\
\hline$r, I V$ & 7 & 0- سيارة خاصة \\
\hline $1 \cdots, \cdots$ & YVY & 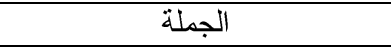 \\
\hline \multicolumn{3}{|c|}{ r-الزمن المستغرق في الوصول إلى مكان العقل } \\
\hline$|\leqslant g| r$ & $r q$ & (أقل من نصف ساعة) \\
\hline$\sum \wedge, 91$ & 1 Ho & (من نصف ساعة - ساعة كاملة) \\
\hline 19.97 & $1 \cdot r$ & (أكثر من ساعة ) \\
\hline $1 \cdots, \cdots$ & YVT & الجملة \\
\hline
\end{tabular}

ب-المتغيرات المتعلقة بالأجر

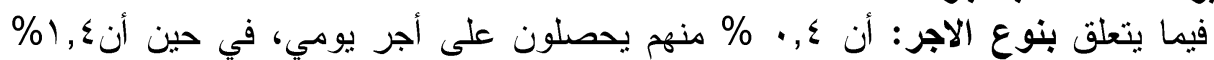

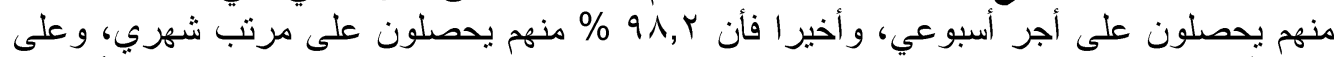

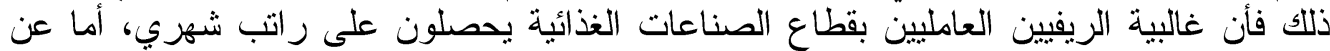

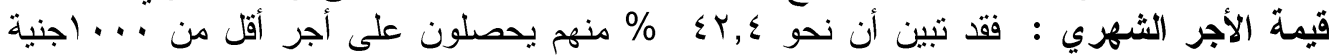

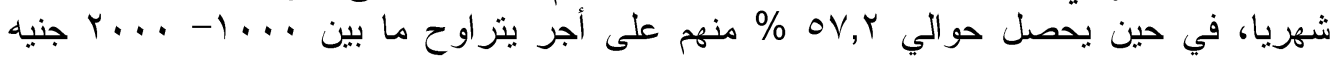

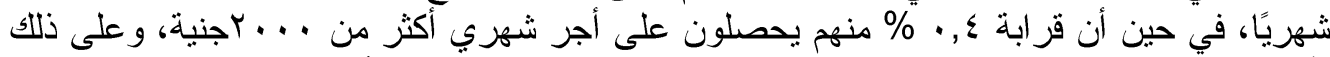

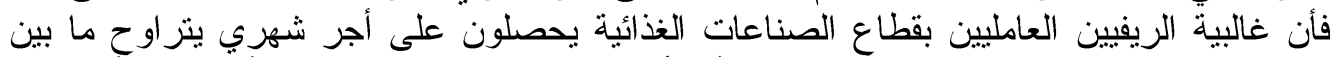

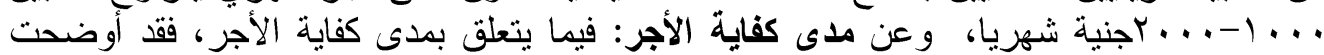

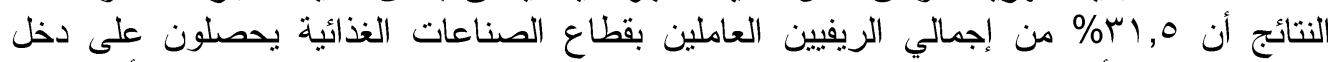

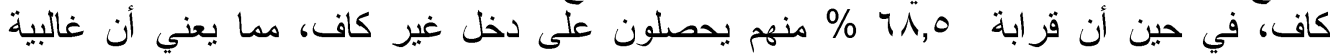

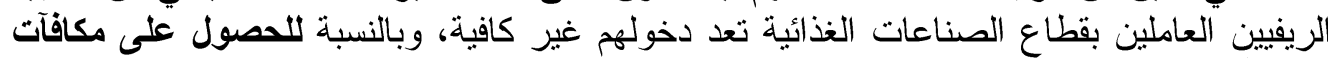

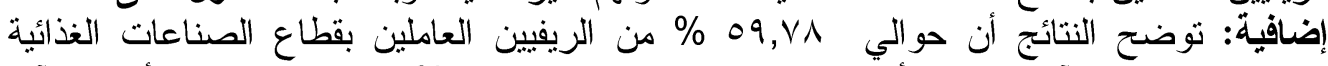

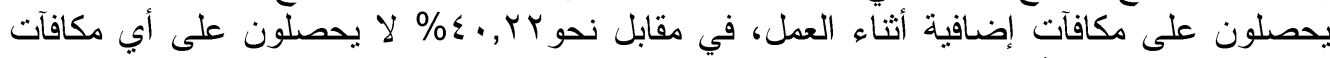

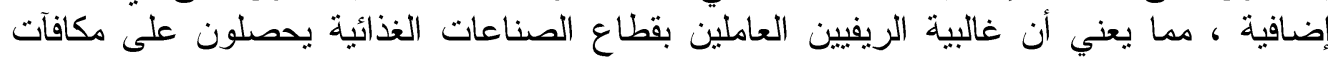

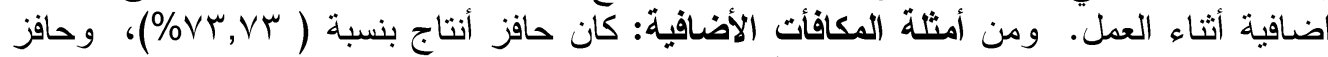

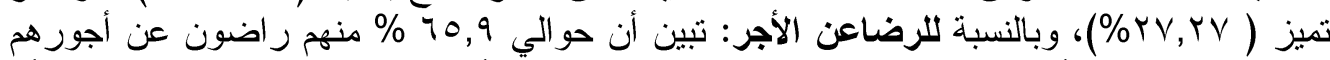

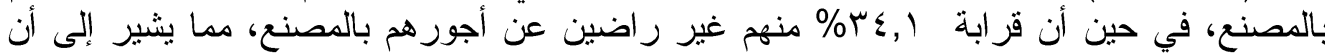
غالبية الريفيين العاملين بقطاع الصناعات الغذائية راضيون رنئ عن أجور هم بالمصنع.

Fayoum J. Agric. Res. \& Dev., Vol. r r, No. r, July, ґ. I^ 
جدول (9): التوزيع العددي والنسبي للريفيين العاملين بقطاع الصناعات الغذائية وفقًا لبعض

\begin{tabular}{|c|c|c|}
\hline$\%$ & العلد & له بالاجر · المتغير \\
\hline \multicolumn{3}{|c|}{ ا-نوع الاجر } \\
\hline$\cdot, \xi$ & 1 & يومي \\
\hline $1, \varepsilon$ & $\varepsilon$ & 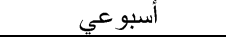 \\
\hline $9 \wedge, Y$ & YVI & مرتب شهري \\
\hline $1 \cdots, \cdots$ & TVY & الجملة \\
\hline \multicolumn{3}{|c|}{ ب-قيمة الأجر الشهري } \\
\hline$\varepsilon r, \varepsilon$ & $11 \mathrm{~V}$ & أقل من ... اجنية \\
\hline$\Delta V, Y$ & 101 & |.......... \\
\hline$\cdot, \underline{\varepsilon}$ & 1 & أكثر من .... بجنية \\
\hline $1 \ldots, \ldots$ & rVT & الجملة \\
\hline \multicolumn{3}{|c|}{ r-مدى كفاية الأجر } \\
\hline 01 & AV & كاف \\
\hline$i \Lambda, 0$ & 119 & غير كاف \\
\hline $1 \ldots$ & $r V T$ & الجملة \\
\hline$\%$ & العدد & المتغير \\
\hline \multicolumn{3}{|c|}{ ع -الحصول على مكافآت إضافي } \\
\hline$\Delta ৭, \vee \wedge$ & $1 \leq$. & يحصل \\
\hline$\varepsilon, Y Y$ & 114 & لايحصل \\
\hline $1, \cdots, \ldots$ & $r V T$ & الجملة \\
\hline \multicolumn{3}{|c|}{ هـ-أمثلة المكافآت الإضافية } \\
\hline$V Y, \wedge Y$ & $1 \cdot r$ & حافز أنتاج \\
\hline$r V, I \leq$ & $r \Lambda$ & حافز تميز \\
\hline $1 \ldots, \cdots$ & $1 \varepsilon$. & الجملة \\
\hline$\%$ & العلد & المتغير \\
\hline \multicolumn{3}{|c|}{ צ- الرضا عن الأجر } \\
\hline 70,9 & IAY & ر راضي \\
\hline$r \leqslant, 1$ & $9 \leq$ & غير راضي \\
\hline $1, \ldots, \ldots$ & YVT & الجملة \\
\hline
\end{tabular}

ج- مخاطر العمل

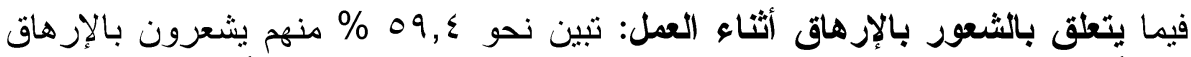

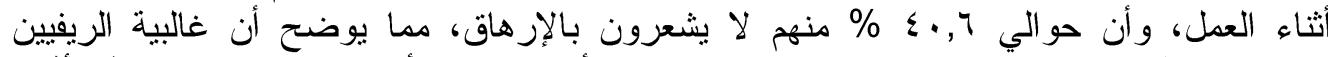

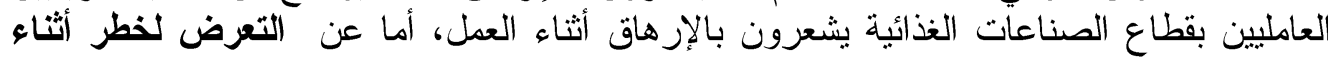

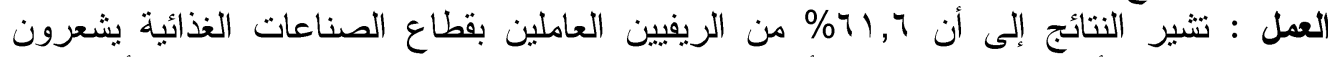

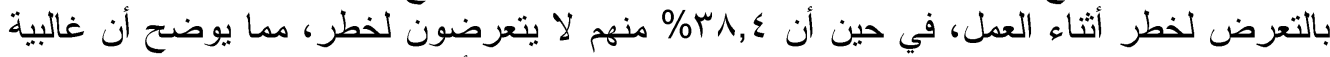

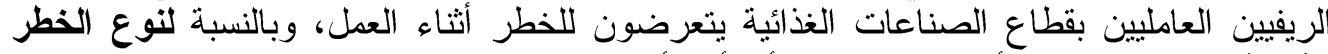

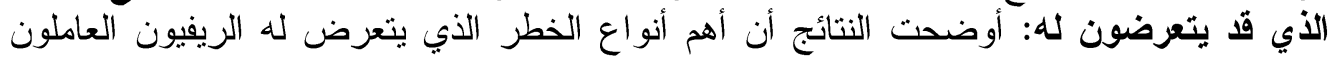

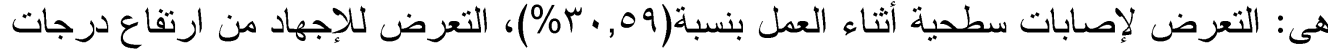

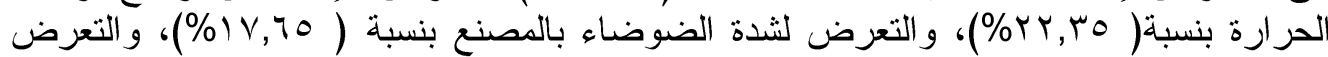

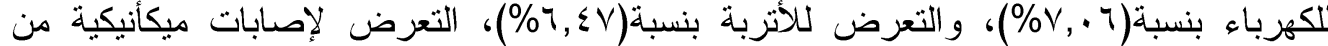

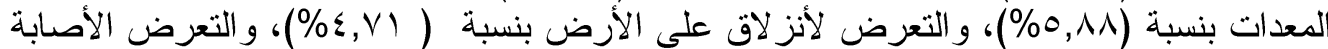

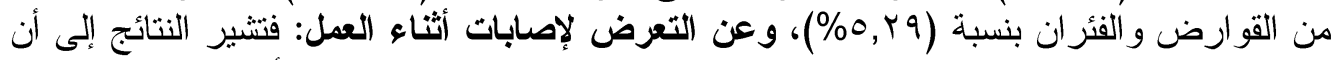
ب rq,V

Fayoum J. Agric. Res. \& Dev., Vol. 'r, No. r, July, r. I^ 


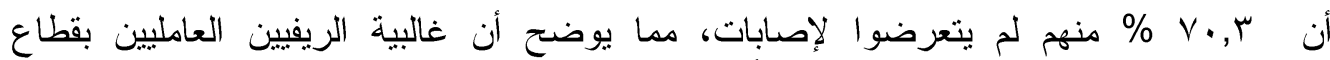

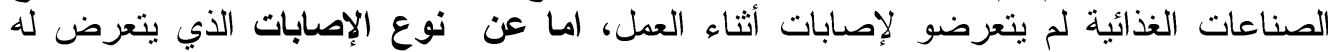

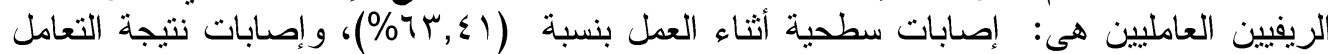

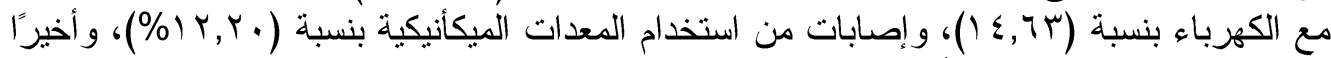

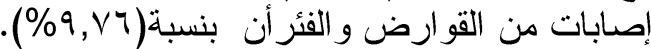

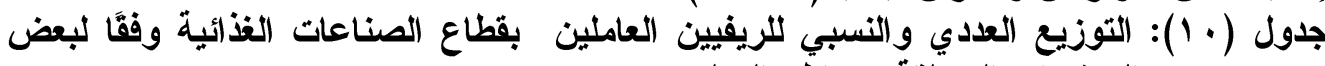

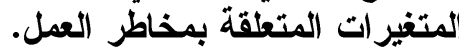

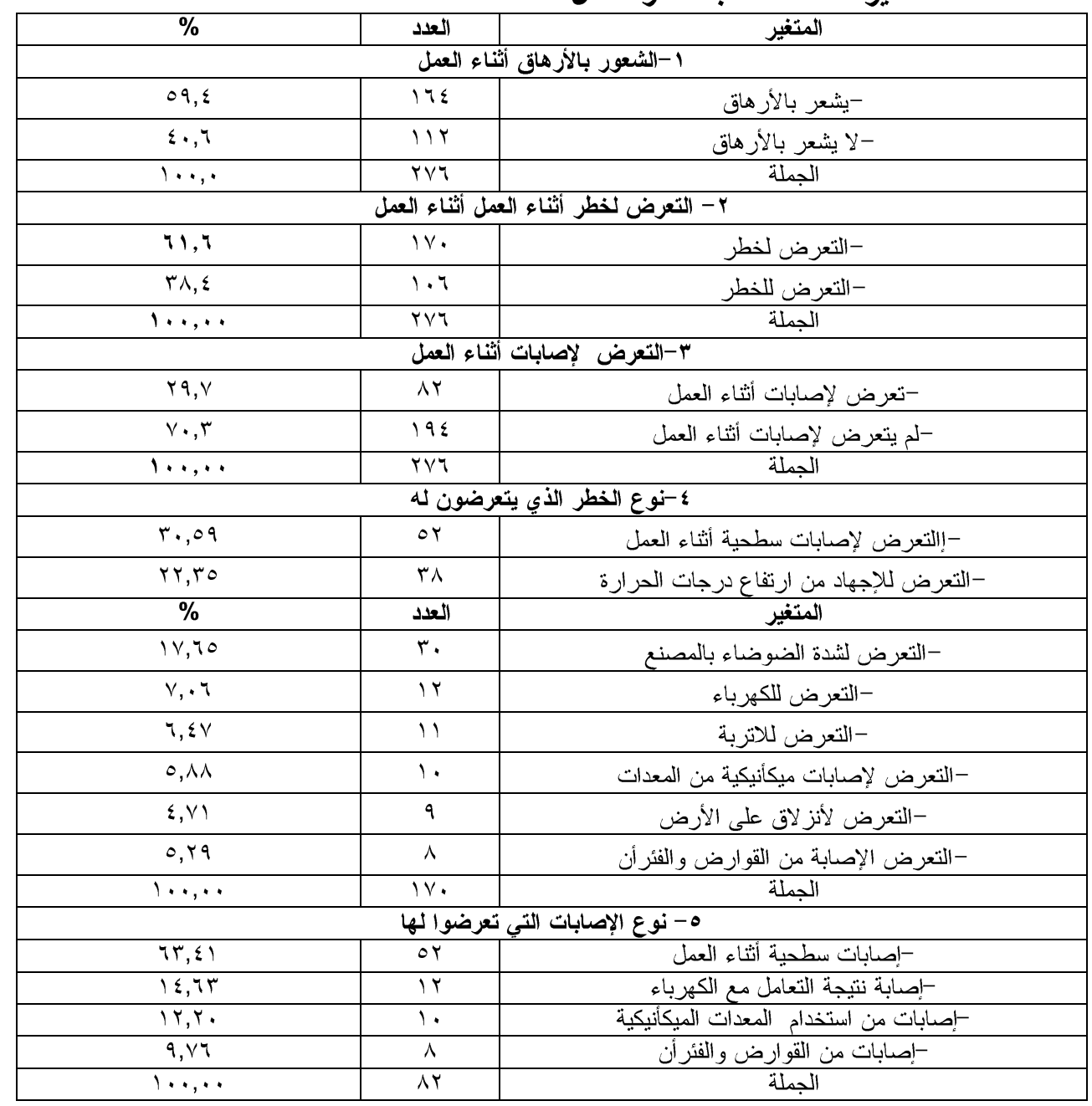

د- المتغيرات المتعلقة بالجزاعات أثناء العمل

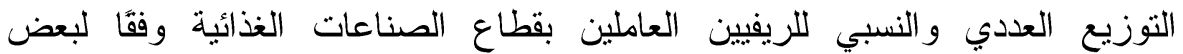

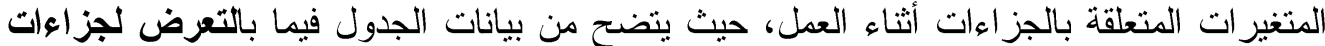

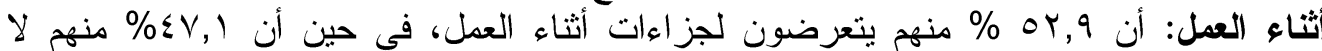

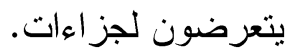

Fayoum J. Agric. Res. \& Dev., Vol. 'r,, No. r, July, ґ. I^ 


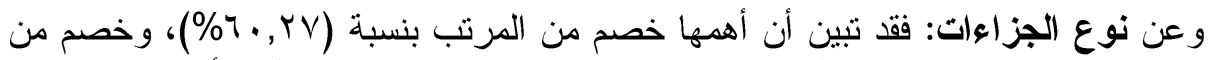

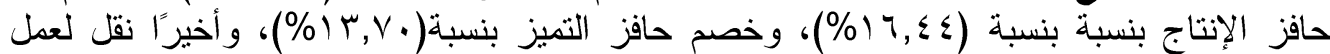

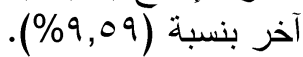

جدول (11): التوزيع العددي والنسبي للريفيين العاملين بقاع العاع الصناعات الغذائية وفقًا لبعض

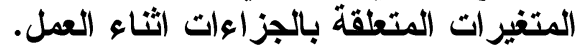

\begin{tabular}{|c|c|c|}
\hline$\%$ & العدد & المتغير \\
\hline \multicolumn{3}{|c|}{ 1-التعرض لجزاءات أثناء العمل } \\
\hline or, 9 & $1 \leq 7$ & - يتعرض \\
\hline$\varepsilon \vee, 1$ & $1 \pi$. & - لا يتعرض \\
\hline $1 \cdots, \cdots$ & rVT & الجملة" \\
\hline \multicolumn{3}{|c|}{ ب-نوع الجزاءات } \\
\hline$T \cdot, Y V$ & $\Lambda \Lambda$ & -خصم من الراتب \\
\hline $17, \leqslant \leqslant$ & $r \varepsilon$ & -خصم من حافز الإنتاج \\
\hline $1 r, v$. & $r$. & -خصم حافز التميز \\
\hline 9,09 & $1 \varepsilon$ & - نَقل لعمل آخر \\
\hline $1 \ldots, \ldots$ & $1 \leq 7$ & الحملة \\
\hline
\end{tabular}

هـ المتغير ات المتعلقة بعدد أيام وساعات العمل، والراحة ، والأجازات

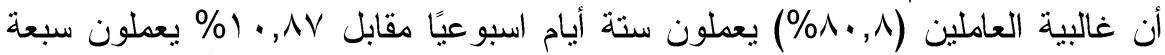

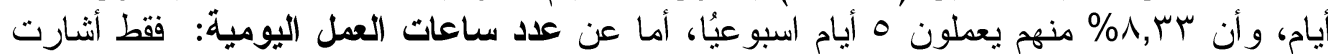

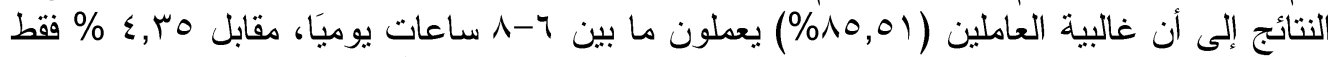

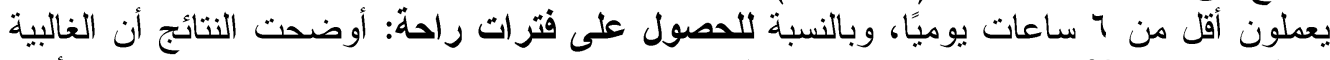

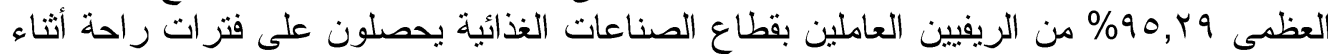

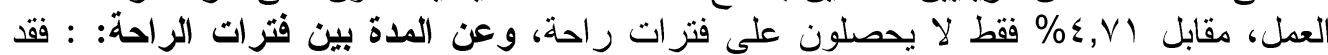

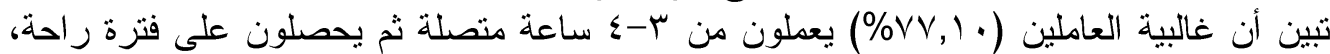

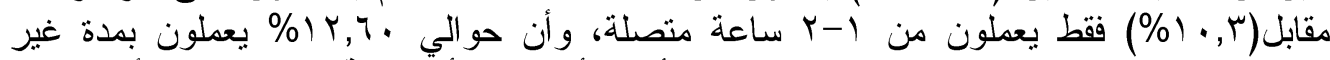

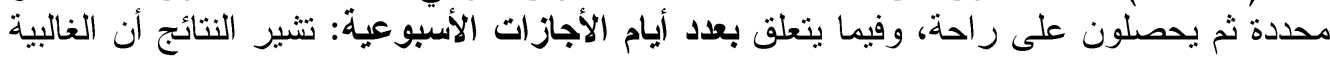

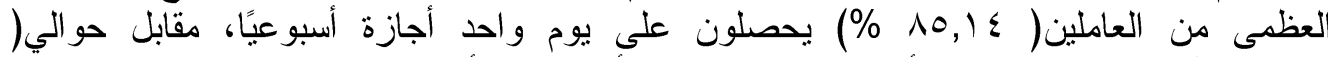

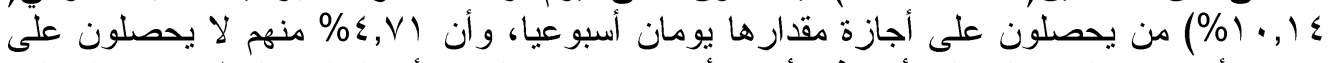

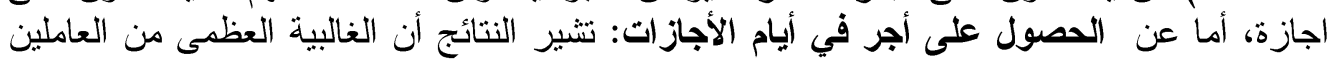

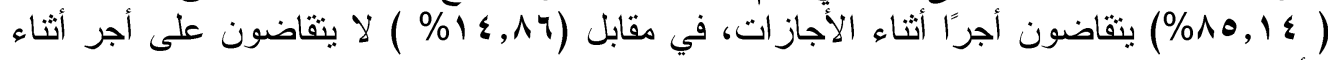

Fayoum J. Agric. Res. \& Dev., Vol. r r, No. r, July, ґ. I^ 


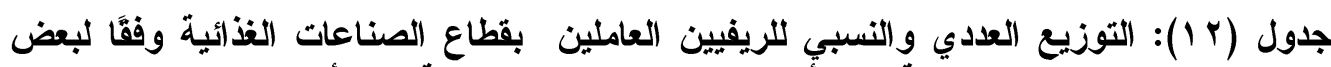

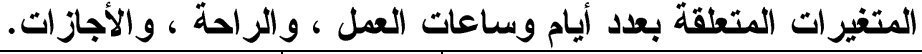

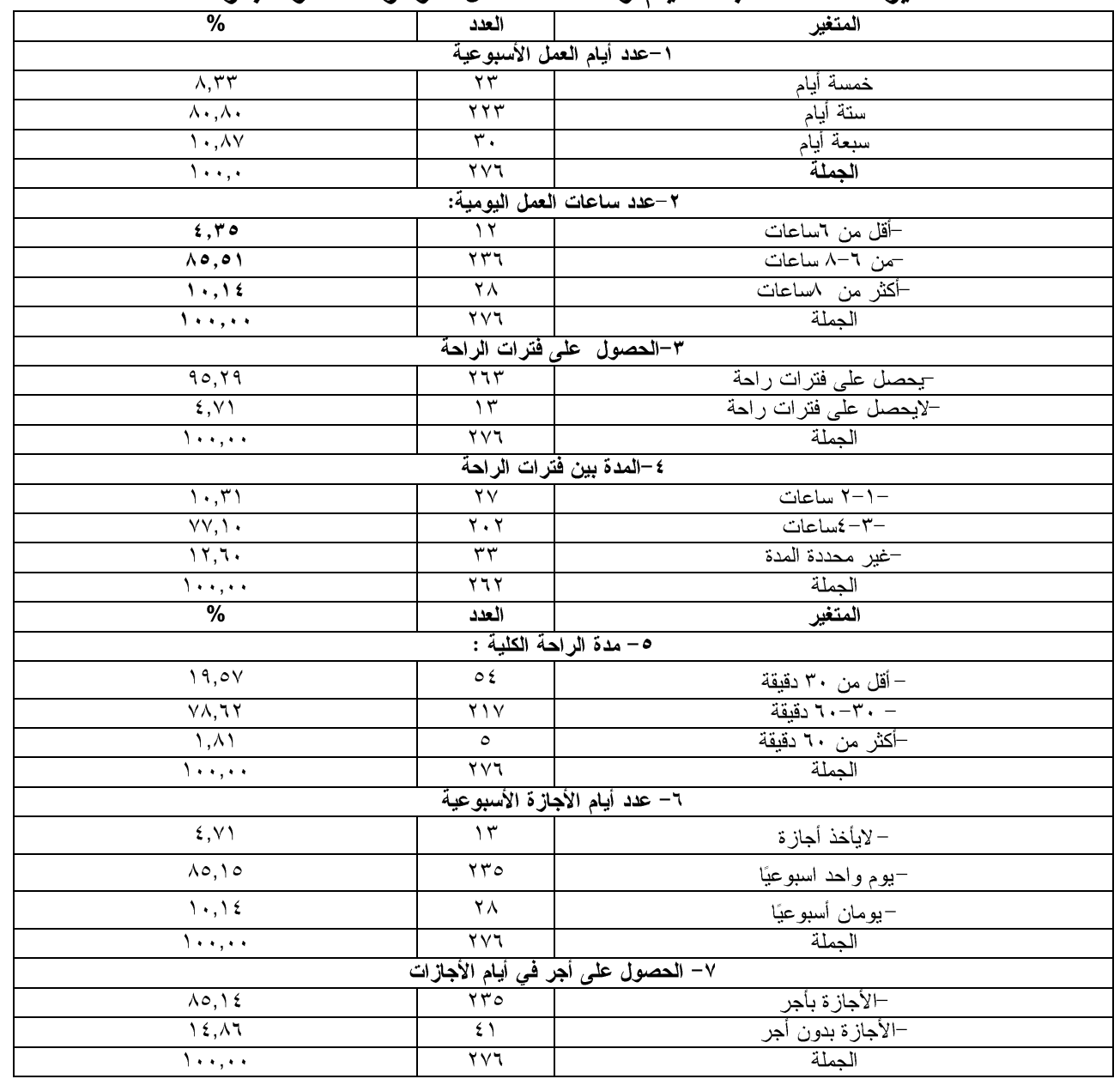

المناقشة

في ضوء النتائج التي أسفرت عنها الدراسة يمكن الخروج بالملاحظات و التفسيرات

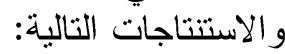

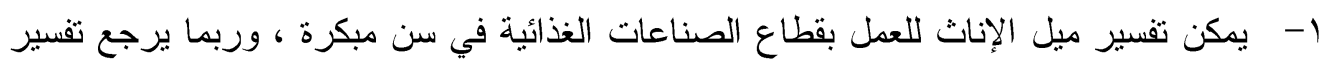

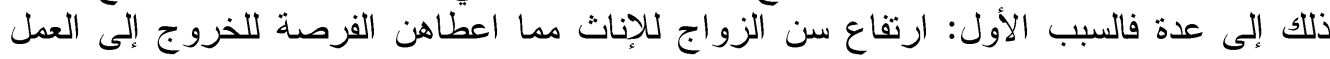

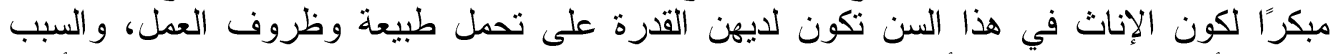

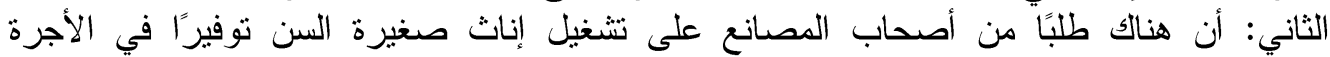

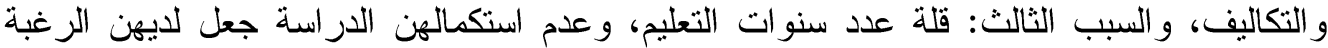
لتحسين دخل الأسرة مما يجعلهم يخرجون إلى سوق العمل مبكرًا.

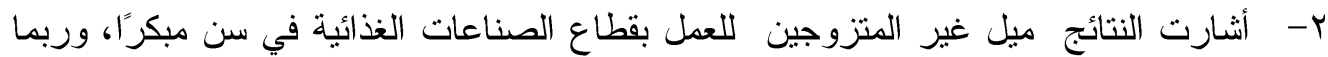

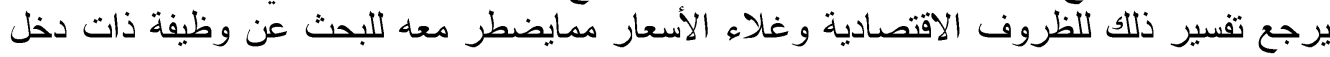

Fayoum J. Agric. Res. \& Dev., Vol. r r, No. r, July, ґ. I^ 
ثابت يحسن من دخله ويساعد به أسرتة على الاستمر ار في المعيشة، وربما يرجع أيضًا إلى أنه أنه

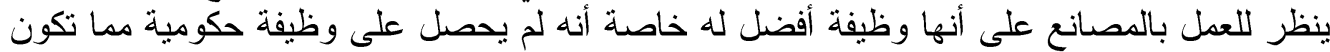

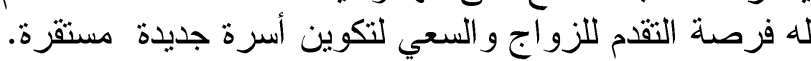

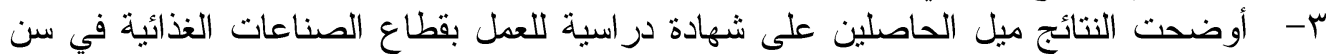

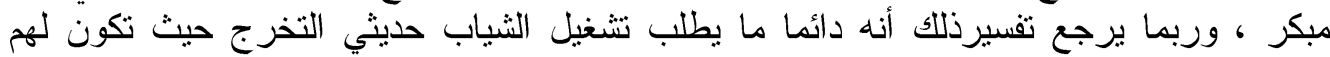

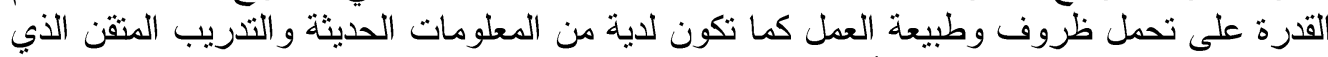

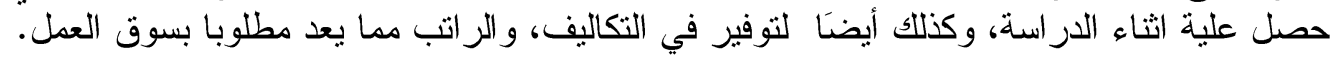

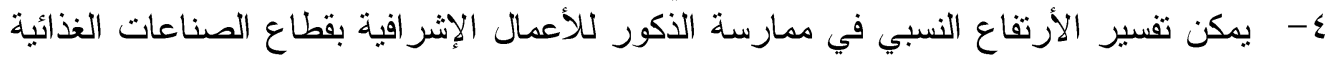

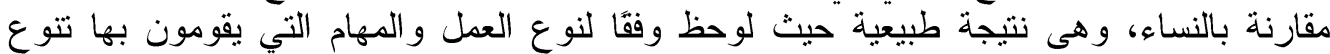

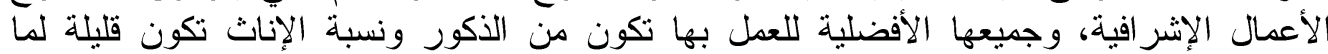

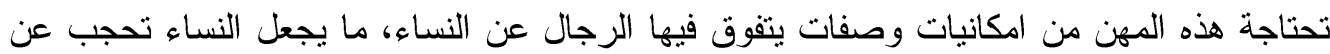

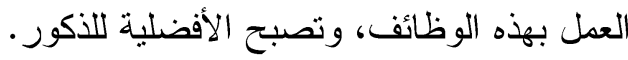

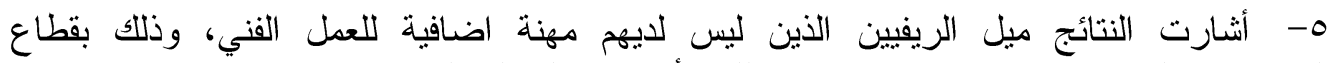

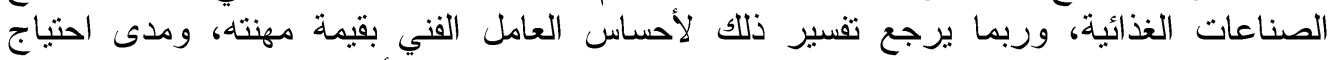

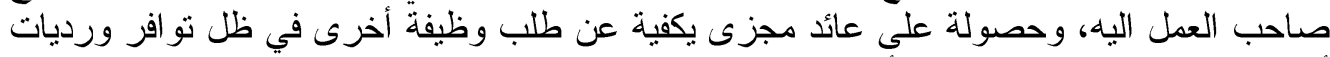

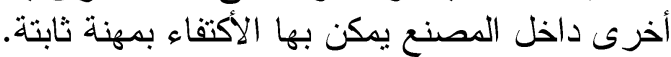

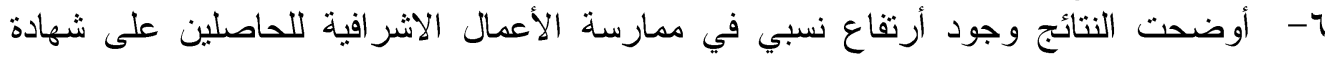

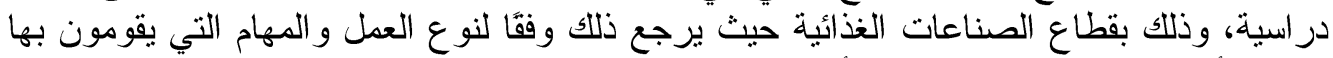

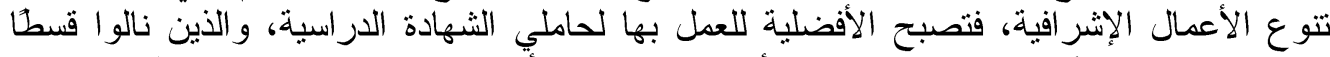

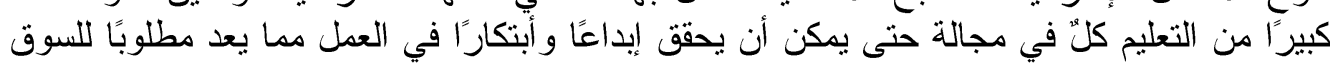
العمل.

V- أظهرت النتائج الارتفاع النسبي في ممارسة الاعمال الفنية لدى العاملين ذوي حجم الأسرة

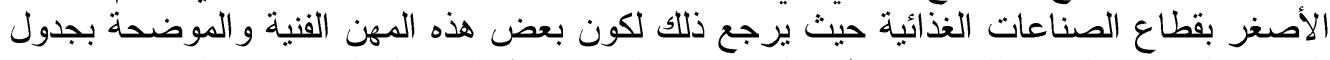

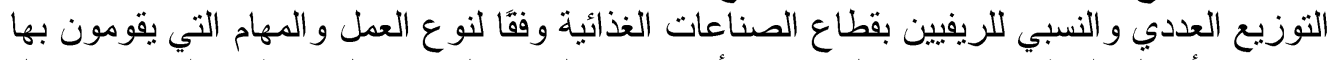

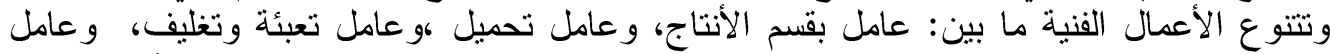

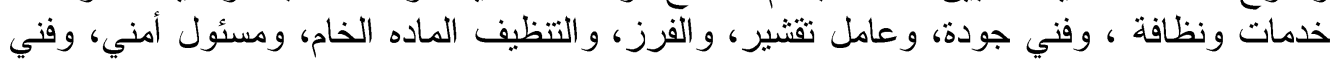

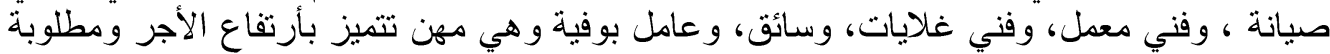

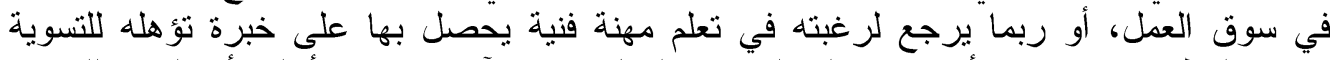

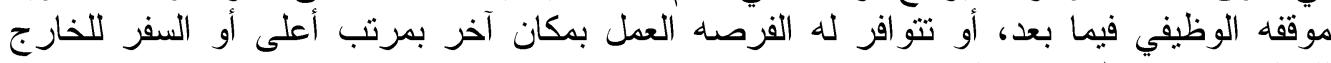
لـعمل بوصفها نظرة مستقبلية.

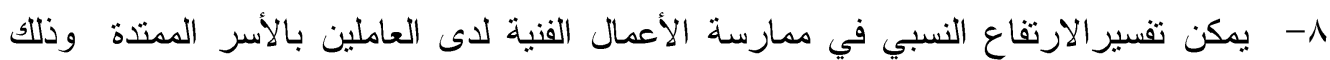

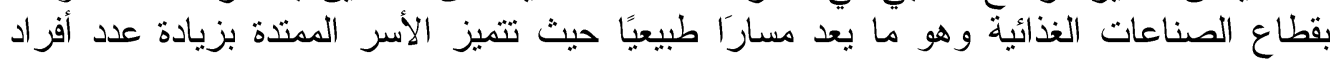

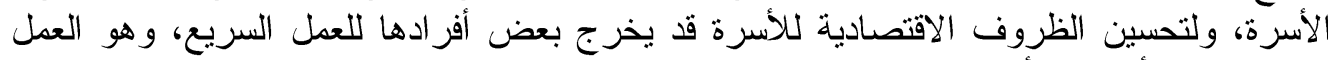

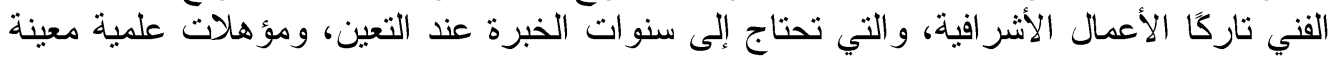

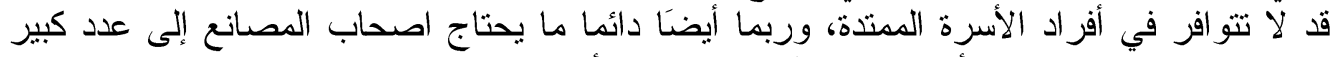

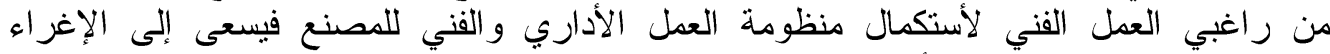

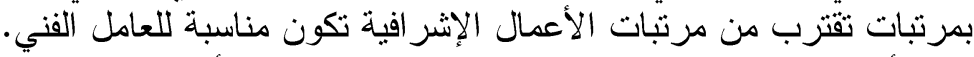

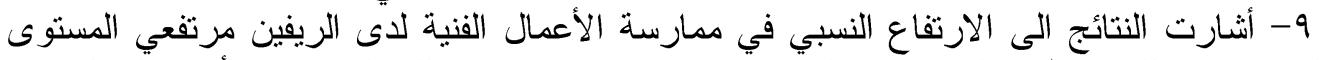

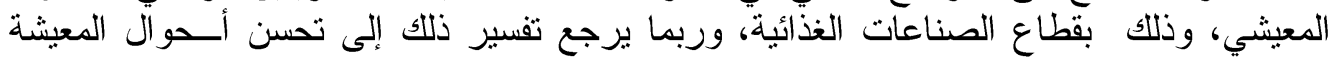

Fayoum J. Agric. Res. \& Dev., Vol. r r, No. r, July, ץ. I^ 
OV

للريفيين العاملين بقطاع الصناعات الغذائية، و الذين يمتهنون المهن الفنية المختلفة نتيجة لحصولهم

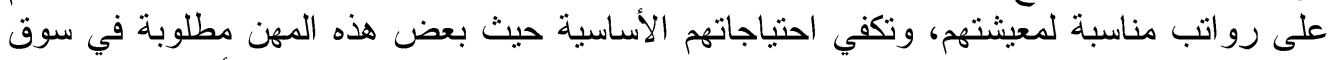

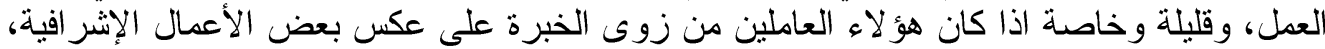
و التي نجد تكدس بها نتيجة تخرج الجامعات للأعداد كبيرة لا يقدر سوق العام العل على استيعابها.

$$
\text { أولاً: المر اجع العربية }
$$

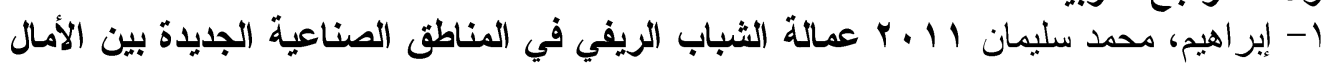

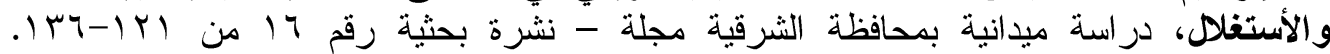

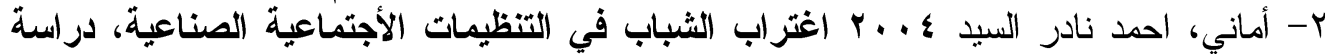

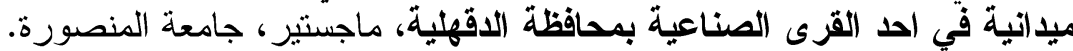

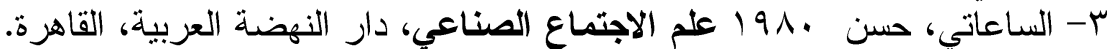

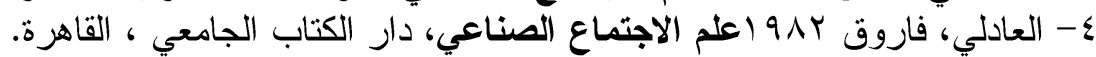

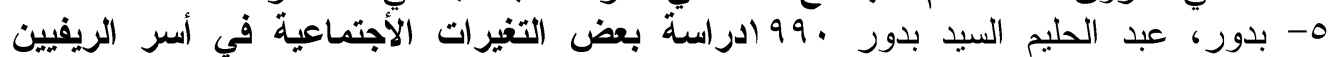

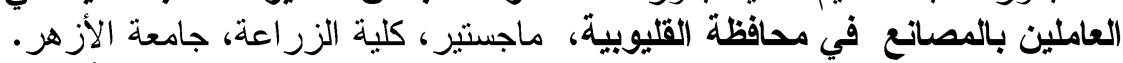

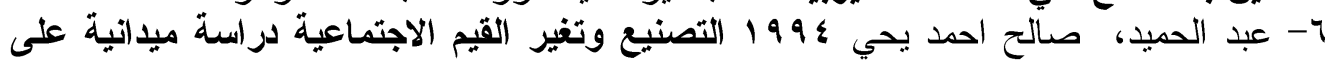
منطقة صناعية واخرى غير صناعية بمحافظة المنيا، دكتور اة، كلية الأداب، المنيا. تانياً: المراجع باللغة الأنجليزية Krejcie\& Morgan)9४."Determining Sample size for Research Activities".(Education and psychological Measurement,\#r·,pp. $T \cdot V$ Lutz, Gene $19 \wedge$ M.understanding social statistics, New york Macmiillan publishing co., Inc

Fayoum J. Agric. Res. \& Dev., Vol. rr, No. ', July, r. IA 


\title{
RURAL PEOPLES LABOR IN FOOD INDUSTRIES IN BENISUEF GOVERNORAT
}

\begin{abstract}
The current study basically aimed at identifying personal and family characteristics actually happened, identify the nature and working conditions of rural food industry, and solve it from their point of view, and may A comprehensive study was two Presidents first section: the total number of rural workers in the food industry with three industrial projects, $r \vee \uparrow$ laborers, section II: of the total number of farmers, a sample size of farmers reached to $r \cdot r$ farmers. Chi-square test and percentages have been used in bringing out these relationships and Kramer laboratories to show the force of these relations.

The results of the study indicated the following:

1- The results of the study by using chi-square showed that there is a significant correlation at a significant level of $\cdot{ }^{\cdot 1}$ or $\cdot . \cdot 0$ between the age of rural workers in the food industry at the beginning of the work and the variables of the study in relation to variables: marital status, educational level, and household size.

r. The results of the study by using chi-square showed that there is a significant correlation at a significant level of $\because \cdot 1$ between the type of work of rural workers in the food industry and both of: gender, additional occupation, family size, family type and living standard.
\end{abstract}

Key words: Rural Development_Agricultural Industry_Industrial Organizations_Rural Labors

Fayoum J. Agric. Res. \& Dev., Vol. r r, No. r, July, ґ. I^ 